\title{
Slip history and dynamic implications of the 1999 Chi-Chi, Taiwan, earthquake
}

\author{
Chen Ji and Donald V. Helmberger \\ Seismological Laboratory, California Institute of Technology, Pasadena, California, USA
}

David J. Wald ${ }^{1}$

U.S. Geological Survey, Pasadena Office, Pasadena, California, USA

Kuo-Fong Ma

Institute of Geophysics, National Central University, Chung-Li, Taiwan

Received 16 January 2002; revised 18 March 2003; accepted 29 April 2003; published 4 September 2003.

[1] We investigate the rupture process of the 1999 Chi-Chi, Taiwan, earthquake using extensive near-source observations, including three-component velocity waveforms at 36 strong motion stations and 119 GPS measurements. A three-plane fault geometry derived from our previous inversion using only static data [Ji et al., 2001] is applied. The slip amplitude, rake angle, rupture initiation time, and risetime function are inverted simultaneously with a recently developed finite fault inverse method that combines a wavelet transform approach with a simulated annealing algorithm [Ji et al., 2002b]. The inversion results are validated by the forward prediction of an independent data set, the teleseismic $P$ and $S H$ ground velocities, with notable agreement. The results show that the total seismic moment release of this earthquake is $2.7 \times 10^{20} \mathrm{~N} \mathrm{~m}$ and that most of the slip occurred in a triangular-shaped asperity involving two fault segments, which is consistent with our previous static inversion. The rupture front propagates with an average rupture velocity of $\sim 2.0 \mathrm{~km} \mathrm{~s}^{-1}$, and the average slip duration (risetime) is $7.2 \mathrm{~s}$. Several interesting observations related to the temporal evolution of the Chi-Chi earthquake are also investigated, including (1) the strong effect of the sinuous fault plane of the Chelungpu fault on spatial and temporal variations in slip history, (2) the intersection of fault 1 and fault 2 not being a strong impediment to the rupture propagation, and (3) the observation that the peak slip velocity near the surface is, in general, higher than on the deeper portion of the fault plane, as predicted by dynamic modeling. INDEX TERMS: 7205 Seismology: Continental crust (1242); 7209 Seismology: Earthquake dynamics and mechanics; 7215 Seismology: Earthquake parameters; KEYWORDS: Chi-Chi earthquake, kinematic rupture, combined inversion

Citation: Ji, C., D. V. Helmberger, D. J. Wald, and K.-F. Ma, Slip history and dynamic implications of the 1999 Chi-Chi, Taiwan, earthquake, J. Geophys. Res., 108(B9), 2412, doi:10.1029/2002JB001764, 2003.

\section{Introduction}

[2] In recent years, geologists and geophysicists have witnessed a revolution in the development and implementation of an array of new tools for measuring motions of the Earth's crust, including global positioning satellites, interferometric synthetic aperture radar, and broadband digital seismic systems, allowing tremendous advances in motion detection accuracy. Japan and Taiwan took the lead in the installation of these instruments, and the recent Chi-Chi, Taiwan, earthquake (1999) sequence produced a remarkable set of data. About 150 GPS static measurements and 200

\footnotetext{
${ }^{1}$ Now at U.S. Geological Survey, Denver Federal Center, Lakewood, Colorado, USA.

Copyright 2003 by the American Geophysical Union. 0148-0227/03/2002JB001764\$09.00
}

strong motion acceleration records at distances $<50 \mathrm{~km}$ are now available for the main event, $M_{W}=7.6$ [Lee et al., 2000; Yu et al., 2001]. Such a data set offers a unique opportunity to understand the earthquake process and the generation of strong ground motions. In particular, we can rely on the GPS data to investigate the fault complexity and static dislocation field and use the strong motion data to constrain the temporal evolution of the rupture involved in producing these offsets.

[3] The Chi-Chi earthquake occurred in the collision zone of the Eurasian plate and the Philippine plate, where the Philippine plate moves with a speed of $7-8 \mathrm{~cm} \mathrm{yr}^{-1}$ in the $\mathrm{N} 305^{\circ} \mathrm{E}$ direction relative to the Eurasian plate (Figure 1) [Seno et al., 1993; Yu et al., 1997]. Such fast relative motion uplifts Taiwan and is presumably the tectonic cause of the large earthquakes visiting the island and adjacent regions. The 1999 Chi-Chi earthquake is the largest inland event occurring in the twentieth century. The event created a 


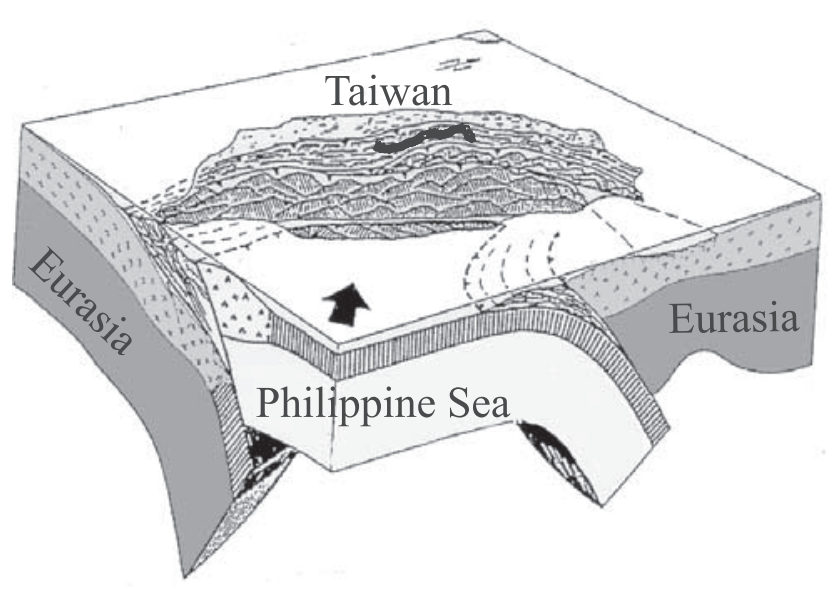

Figure 1. Tectonic framework of the Taiwan region. The bold line indicates the surface break caused by the 1999 Chi-Chi earthquake. Note the complex plate interaction between the Philippine and Eurasian plates. Reprinted from Angelier [1986], with permission from Elsevier.

100-km-long surface trace, most of which was along a known active fault, the north-south trending Chelungpu fault (Figure 2) [Lee et al., 2000]. The surface slip amplitude increased from south to north and reached a peak of nearly $10 \mathrm{~m}$ where the peak ground velocity was $\sim 4 \mathrm{~m} \mathrm{~s}^{-1}$, the largest ever recorded. However, the peak accelerations were recorded in the middle and southern sections of the fault, and there were only relatively modest values associated with the largest surface breakage. Ma et al. [2000] suggested that this behavior is correlated with the variation in rupture velocity, where the initial rupture started at $2.5 \mathrm{~km} \mathrm{~s}^{-1}$, increased to $4.0 \mathrm{~km} \mathrm{~s}^{-1}$, and then decreased to $1.2 \mathrm{~km} \mathrm{~s}^{-1}$ in the region of largest slip. Their study assumed rupture on a rectangular fault plane to model the strong motions and explained most of the complexity of the recordings in terms of localized asperities with large slip offsets. A similar result was obtained by Chi et al. [2001], where many local strong motion records were well matched. However, the geodetic data (GPS) require a more complex rupture process involving multiple fault planes, as in the analysis of the 1992 Landers [e.g., Wald and Heaton, 1994] and the 1999 Hector Mine [e.g., Ji et al., 2002b] earthquakes. In particular, after the right angle turn near the northern end of the fault the surface break actually extends $\sim 12 \mathrm{~km}$ to the east (Figure 1) and requires significant moment release along this portion, according to an analysis by Johnson et al. [2001]. They model this fault bending by introducing three planes and by inverting the GPS data (static field), assuming a half-space crustal model. Ji et al. [2001] found that the modeling error could be greatly reduced by assuming a more realistic, layered crust (see Table 1) and by approximating this geometry with two rectangular fault planes, as displayed in Figure 2. The motions on these planes produced a "wedge-shaped" up-lifted block near the northern end, as discussed by $J i$ et al. [2001]. Here we investigate the kinematic rupture history of the Chi-Chi earthquake with this new fault geometry and analysis of the waveform data as a continuation of our previous static study [ Ji et al., 2001] (hereinafter referred to as Part I).
[4] The joint inversion of both the static and dynamic data requires considerable care and attention to the faulting geometry, primarily due to the unprecedented abundance of near-source data. For such a complex inverse problem we apply a new set of inversion tools developed by $J i$ et al. [2002a]. By combining a wavelet transform approach with a simulated annealing algorithm, we demonstrate that our inversion results are robust enough to independently predict the teleseismic waveforms to a high degree of accuracy.

\section{Data}

[5] We use 119 three-component GPS measurements from the data set collected by the Institute of Earth Sciences, Academia Sinica [Yu et al., 2001], for static constraints as discussed in Part I. Even though Yu et al. [2001] noted that the afterslip in the first few days following the main shock was included in the final estimates of coseismic displacements in some epoch-surveyed stations, the effect is quite small for most stations $(<5 \%)$. This suggests that the static field measured by GPS is only slightly contaminated by the afterslip and that the static data can be combined with waveform records to constrain the fault model. We will address the issue of afterslip later.

[6] Waveforms recorded at 36 strong motion stations (Figure 2) are used in the inversions. This data set was subdivided into three groups. Group 1 includes all stations (open triangles) that are directly above the assumed fault planes discussed in section 3. Group 2 is composed of 13 stations (solid triangles) which are located on the western side of the Chelungpu fault (footwall side) and within $20 \mathrm{~km}$ of the surface break (thick trace). The last group includes 12 stations (squares) that form a rather uniform array covering the rest of the fault plane. It is noteworthy that the stations of group 2 are located on the foreland sedimentary basin [e.g., Kao and Chen, 2000].

[7] Because of a Y2K problem, some strong motion stations did not have the correct trigger times [Huang, 2000]. Fortunately, the first arrival of each record can be picked easily because the records include a 20 -s preevent memory, and the first arrivals are impulsive. Huang [2000] suggested a possible way to correct for timing. He first picked the arrival time of each record and then aligned it with the synthetic first arrival calculated with the onedimensional (1D) layered Taiwan model. After such processing the error in the starting time is $<1 \mathrm{~s}$ [Huang, 2000]. Here we use a similar approach but based on a 1D central Taiwan model [Ma et al., 1996] (Table 1). It turns out that the corrections to the hanging wall and distant stations are small but become significant for some footwall stations. These issues were discussed at length by Chi et al. [2001].

[8] All strong motion records are integrated to ground velocity. In our approach the wavelet transform is used to further decompose the waveforms into wavelets, and the wavelet coefficients are used to constrain the fault model [Ji et al., 2002a]. Because of the complex tectonic activity, the velocity structure in central Taiwan is more complex than the assumed 1D layered velocity model. Thus we limit the frequency contents of useful wavelets. For the stations of groups 1 and 2 we use the coefficients of the wavelets with a scale not smaller than $1.6 \mathrm{~s}$. For the stations of group 3 we use the coefficients of the wavelets not smaller than $3.2 \mathrm{~s}$. In practice, we note that the waveforms of the hanging wall 


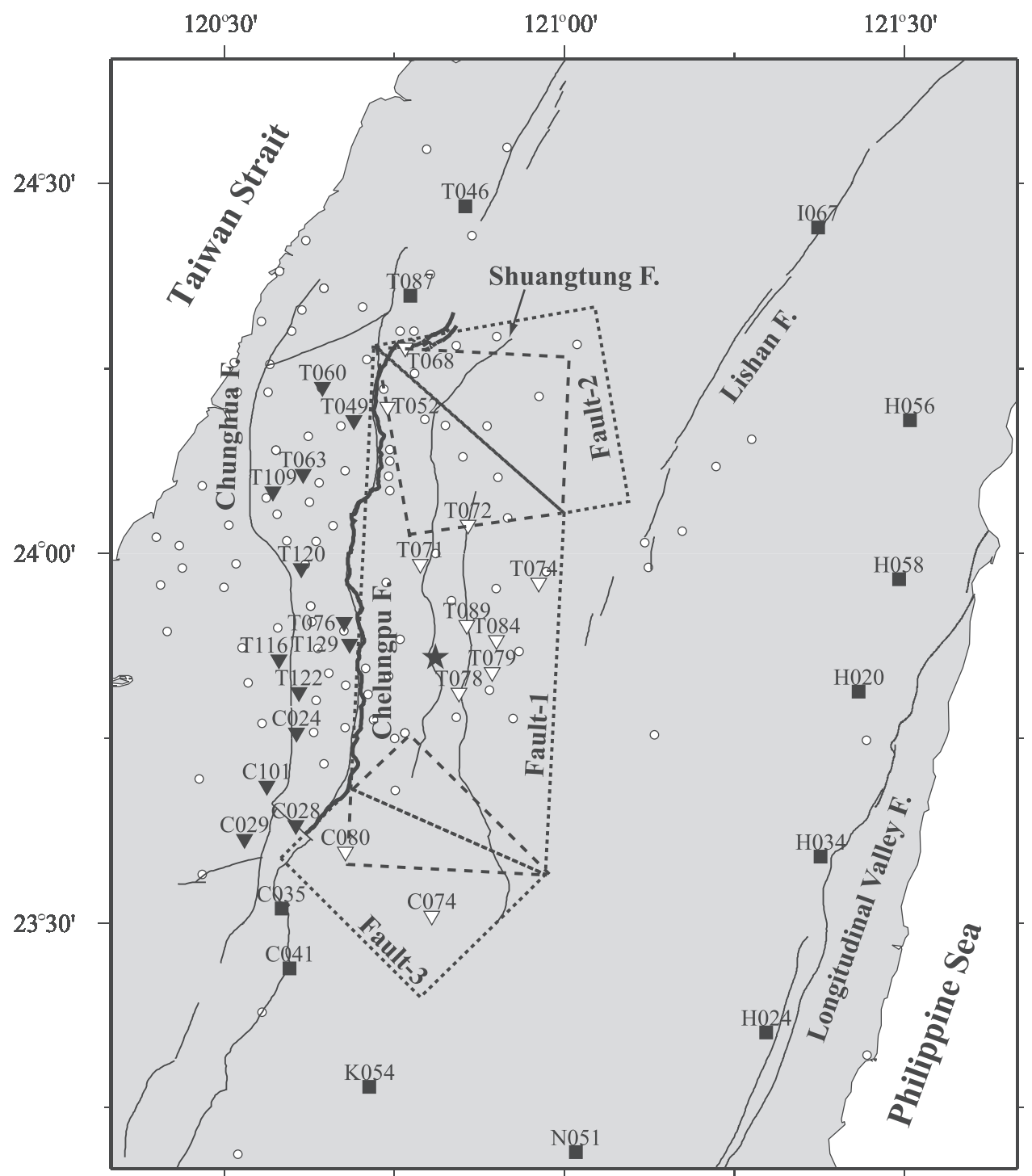

Figure 2. Fault geometry of the Chi-Chi earthquake. Three rectangular dashed boxes display the map projection of the preferred fault geometry with three fault segments: fault 1 , fault 2 , and fault 3 . The rupture of the Chi-Chi event initiates at fault 1 , as indicated by a star. The bold lines show the surface break of this event, and the thin lines show the adjacent thrust faults. Selected GPS (open circles) and strong motion (symbols) stations are also indicated. The latter are further divided into three groups, with open triangles as group 1, solid triangles as group 2, and squares as group 3. Note that the GPS stations have much better coverage in the northeastern portion of the rupture.

stations seem coherent in contrast to the waveforms of the footwall stations, which appear to be affected by the 3D basin structure. Thus we assigned the hanging wall records twice the weight of the records in groups 2 and 3. Twenty-one teleseismic $P$ waveforms and $18 \mathrm{SH}$ waveforms were downloaded from the Incorporated Research Institutions for Seismology data center. We removed their instrument responses and then converted them to ground velocity. This far-field data set is not used directly to constrain the model. Instead, we use it later to verify the preferred model constrained by local observations, i.e., the GPS measurements and strong motion waveforms.

\section{Fault Geometry and Method}

[9] The fault geometry constrained by our previous static study (Part I) is used in this study (Figure 2). We use three planar fault segments (faults 1,2, and 3) to approximate the rupture plane during the Chi-Chi main shock. Fault 1 is along the north-south trending Chelungpu fault and has a strike of $\mathrm{N} 3^{\circ} \mathrm{E}$. Fault 2 follows the east trending surface

Table 1. Central Taiwan Crust Model

\begin{tabular}{ccccc}
\hline $\begin{array}{c}V_{p}, \\
\mathrm{~km} \mathrm{~s}^{-1}\end{array}$ & $\begin{array}{c}V_{s}, \\
\mathrm{~km} \mathrm{~s}^{-1}\end{array}$ & $\begin{array}{c}\rho, 10^{3} \\
\mathrm{~kg} \mathrm{~m}^{-3}\end{array}$ & $\begin{array}{c}\text { Thickness, } \\
\mathrm{km}\end{array}$ & $\begin{array}{c}\text { Rigidity, } \\
10^{10} \mathrm{~N} \mathrm{~m}^{-2}\end{array}$ \\
\hline 3.50 & 2.00 & 2.0 & 1.0 & 0.8 \\
3.78 & 2.20 & 2.3 & 3.0 & 1.1 \\
5.04 & 3.03 & 2.5 & 5.0 & 2.3 \\
5.71 & 3.26 & 2.6 & 4.0 & 2.8 \\
6.05 & 3.47 & 2.6 & 4.0 & 3.1 \\
6.44 & 3.72 & 2.6 & 8.0 & 3.6 \\
6.83 & 3.99 & 3.0 & 5.0 & 4.8 \\
7.28 & 4.21 & 3.0 & 0.0 & 5.3 \\
\hline
\end{tabular}


rupture at the northern end of the rupture and has a strike of $\mathrm{N} 80^{\circ} \mathrm{E}$. Fault 3 is added to match the bend in the surface break at the southern end and has a strike of $\mathrm{N}^{\circ} 5^{\circ} \mathrm{E}$. All fault segments have the same dip angle of $30^{\circ}$, as discussed in Part I. Finally, we extend the three fault segments from the surface to a depth of $17 \mathrm{~km}$; preliminary models extending below this depth demonstrated that this depth is adequate. We divide the fault plane into small rectangular regions of equal area, or subfaults. The response of each subfault can be represented as the function of its slip amplitude, rake angle, risetime function, and rupture velocity. Thus the motions (displacements) can be generated by a double summation over rows $\mathbf{n}$ and columns $\mathbf{m}$ :

$u(t)=\sum_{j=1}^{\mathbf{n}} \sum_{k=1}^{\mathbf{m}} D_{j k}\left[\cos \left(\lambda_{j k}\right) Y_{j k}^{1}\left(V_{j k}, t\right)+\sin \left(\lambda_{j k}\right) Y_{j k}^{2}\left(V_{j k}, t\right)\right] * \dot{S}_{j k}(t)$,

where $D_{j k}$ is the slip amplitude (offset), $\lambda_{j k}$ is the rake angle, $S_{j k}$ is the risetime function, $V_{j k}$ is the average rupture velocity between hypocenter and subfault $j k$, and $Y_{j k}^{i}\left(V_{j k}, t\right)$ are subfault Green's functions. Each subfault Green's function is represented as a summation of 81 point sources to take the directivity inside a subfault into account, which is very important in modeling the hanging wall stations, where a single-point source representation for a subfault is inadequate. The details of the procedure we use for generating the subfault responses are given by $J i$ et al. [2002a].

[10] The seismic data prove much more difficult to model relative to the static data because of their sensitivity to crustal structure and its intrinsically complex nature; that is, the near-field and far-field contributions from several subfaults interfere with each other to produce patterns that are controlled by both the spatial and temporal slip functions. We attempt to reduce this interference by choosing a relatively simple function to simulate the slip history at each point of the fault plane. Following the work of Liu and Archuleta [2000] and Zeng and Chen [2001], we used an asymmetric cosine function to approximate the derivative of the risetime, or the normalized local slip rate function (Figure 3):

$$
\dot{S}(t)= \begin{cases}\frac{1}{t_{s}+t_{e}}\left[1-\cos \left(\frac{\pi t}{t_{s}}\right)\right] & 0<t<t_{s} \\ \frac{1}{t_{s}+t_{e}}\left[1-\sin \left(\frac{\pi\left(t-t_{s}\right)}{t_{e}}\right)\right] . & t_{s}<t<t_{s}+t_{e} \\ 0 & t>t_{s}+t_{e}\end{cases}
$$

The shape of the slip rate function is determined by two parameters. The first one is called the starting-phase time $\left(t_{s}\right)$, which is used to measure the duration from the rupture initiation to the time with maximum slip velocity; the second one is the end-phase time $\left(t_{e}\right)$, used to measure the duration until the rest of the slip is accomplished. Such an approach permits the modeling of asymmetric "pulse-like" ground velocity waveforms that are clearly displayed by several observations near the surface break. Even though this approach has one more degree of freedom than the symmetric cosine function used in our previous study [ $\mathrm{Ji}$ et al., 2002a], it is still far fewer than the multiple time

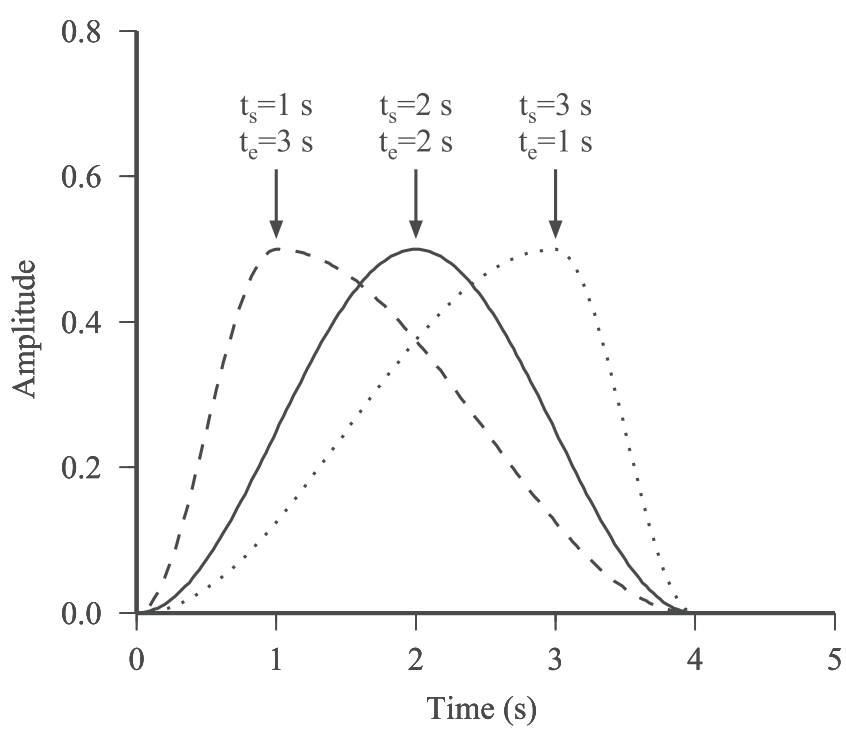

Figure 3. Risetime characterization. Three normalized slip-rate functions having the same width but with different combinations of starting-phase $\left(t_{s}\right)$ and end-phase $\left(t_{e}\right)$ times are shown.

window approach [Ma et al., 2001; Chi et al., 2001]. Because of this simple parameterization, our inversion only intends to investigate the first-order slip characteristics of rupture. The real slip process may be more complex, and simple parameterization will cause the misfit of strong motion waveforms to some extent. However, we will show that such a simple representation can, in fact, give a very good waveform fit for most strong motion waveforms and predicts the teleseismic waveforms quite accurately.

[11] All subfaults have the same dimension of $3.8 \times$ $3.7 \mathrm{~km}$, which is compatible with our static-only inversion (Part I) and with several previous studies [e.g., Ma et al., 2001; Chi et al., 2001]. Even though three fault planes are subdivided into a total of 360 subfaults, not all of them are used to generate the synthetic response. In Part I we confirmed a physically plausible assumption that slip was limited to the surface of a "wedge-shaped" block and not to subfaults below the intersection of the planes in the north and south (see Figure 2). Thus we set the slip amplitudes of the subfaults below the wedge surface to zero. The number of contributing subfaults is then limited to 324, and the number of entire free parameters is only 1620 .

[12] For all fault segments we allow the slip amplitude of each subfault to vary from 0 to $24 \mathrm{~m}$. On faults 1 and 3 the rake angle is fixed in a range from $0^{\circ}$ to $180^{\circ}$ to suppress downward slip not observed on the surface. On fault 2 we let the rake angle vary from $0^{\circ}$ to $360^{\circ}$ because there are some surface observations of normal faulting. We let the average rupture velocity vary from 1.5 to $3.0 \mathrm{~km} \mathrm{~s}^{-1}$. The simulated annealing method [Sen and Stoffa, 1991] is applied to find a global minimum of an error function, represented as

$$
\operatorname{err}_{\mathrm{wf}}+W_{\mathrm{st}} \mathrm{err}_{\mathrm{st}}+W_{c}(\text { constraints })=\text { minimum }
$$

Here $\operatorname{err}_{\mathrm{wf}}$ and $\mathrm{err}_{\mathrm{st}}$ are objective functions of seismic waveforms and static displacements, respectively [ $\mathrm{Ji}$ et al., 
2002a]. Two types of constraints are also chosen: one that minimizes the difference between the slip on adjacent subfaults with a Laplacian operator [e.g., Du et al., 1992] and a second that minimizes the total moment [Hartzell et al., 1996]. Both of these constraints become less important as the quantity and quality of data is increased. Moreover, the latter moment dependence has been greatly reduced by the normalization of amplitude procedure discussed in the method paper [ $\mathrm{Ji}$ et al., 2002a]. The two weighting parameters $W_{\text {st }}$ and $W_{c}$ thus affect the overall results in contrasting ways. Several inversions with differing combinations of weighting $W_{\text {st }}$ and $W_{c}$ were performed, ranging from 2 to 0.5 for $W_{\text {st }}$ and from 0.01 to 1 for $W_{c}$. Here we only present the result with $W_{\mathrm{st}}=1$ and $W_{c}=0.1$. Decreasing the latter to 0.01 does not change the waveform fits much, but the slips at adjacent subfaults are less cohesive. Reducing $W_{\text {st }}$ does improve some waveform fits but not in the group 1 data set. Thus we prefer a solution that is more dependent on the hanging wall strong motion records (group 1) and on the static field.

\section{Modeling the Data}

[13] The preferred model constrained by the static and strong motion data is displayed in Figure 4. The total moment release is $2.7 \times 10^{20} \mathrm{~N} \mathrm{~m}$, with the rigidity computed from the 1D central Taiwan model (Table 1). The slip distribution is close to the result of the static inversion (Part I), with relatively small offsets near the hypocenter and a large triangular-shaped asperity with an apex at a depth of $\sim 15 \mathrm{~km}$. This result is similar to other models based on seismic data alone, too [e.g., Ma et al., 2000; Chi et al., 2001]. However, the asperity in our model involves both fault 1 (Chelungpu fault) and fault 2. In fact, the subfault with maximum slip $(18 \mathrm{~m})$ is located on fault 2, where the surface break bifurcates and two branches separate by $\sim 1 \mathrm{~km}$. The slip there is not always pure thrust, and in fact, there is a small piece of fault 2 displaying downward motion to fit one of the GPS measurements. However, we cannot entirely remove the probability that this motion could also be caused by some associated slip on the ShuangTung fault (K. Sieh, personal communication, 2001) or by some other complexity in the fault geometry not addressed here.

[14] The comparison of synthetic static displacements and GPS measurements is displayed in Figure 5. In general, the new model can explain the GPS observations nearly as well as the model constrained by the geodetic data alone (Part I). However, some local discrepancies are apparent, particularly in the region around the hypocenter, which is probably due to the afterslip, as suggested by $Y u$ et al. [2001]. Another region showing misfit is at the eastern end of the surface break (Figure 5). Both data and results of Part I show small vertical motions but not in the model of the combined inversion. This reflects the conflict between static and strong motion data near the northern portion of the fault and is probably caused by our simplified fault plane that only approximates the complexity of the fault trace.

[15] The fits to the waveform data are displayed in Figure 6. In order to be compatible with the information used in the inverted fits, we low-pass filtered the data and synthetics before the comparison. For hanging wall and footwall stations (group 1 and 2) a low-pass filter with a corner frequency of $0.8 \mathrm{~Hz}$ was chosen, which is the highest-frequency content in the smallest-scale wavelet used, i.e., scale $s=1.6$ s. For the distant records (group 3) the corner frequency is $0.4 \mathrm{~Hz}$. The inverted model can explain the hanging wall and distant records very well, but it does not reproduce all of the details of the footwall records (group 2, Figure 6b). Weighting these waveforms more did not generally improve these fits, which probably means that the simple 1D velocity model used is not sufficient for modeling the complex 3D sedimentary basin structures situated to the west of the Chelungpu fault [e.g., Kao and Chen, 2000].

[16] Stations T052 and T068 recorded the largest seismic ground velocities to date. Even though only the velocity records at these two stations are used to constrain the slip history (Figure 4), the displacements and accelerations generated by simple integration and one derivative fit the data quite well (Figure 7a). For a comparison we have included the normalized slip rate functions of the subfaults directly below stations T052 (on fault 1) and T068 (on fault 2) into Figure 7. Both of them have a length of $6 \mathrm{~s}$, but their shapes are different. The subfault beneath station T052 has a symmetric slip rate function, while that beneath station T068 has a much shorter starting time $\left(t_{s}\right)$. These two shapes are very similar to the shapes of the vertical velocity records but are simpler and narrower than the horizontal records. Such phenomena can be explained intuitively by the different radiation patterns of $P-S V$ waves and $S H$ waves. Note that when a hanging wall station is near the surface break, it is close to the nodal plane of both far-field $P$ and $S V$ radiation generated by the slip on the distant subfaults and is thus dominated by the relatively simple near-field pulses. However, the far-field $\mathrm{SH}$ wave radiation has the maximum amplitude, and therefore the horizontal components are influenced more by the distant subfaults than by the vertical component. In short, the hanging wall vertical records of a thrust event become important in reducing the trade-offs in the inverse problem. Unfortunately, the hanging wall vertical records were not used in the several previous Chi-Chi earthquake studies [e.g., Chi et al., 2001; Zeng and Chen, 2001]. Perhaps this bias against vertical records is caused by the difficulties encountered in previous studies of mostly strike-slip events, where the vertical components are small in amplitude and hard to model with the simple $1 \mathrm{D}$ structures.

[17] Theoretically, the fault model constrained by local data sets should, also, be able to explain the far-field observations. However, using such data as an independent verification of a proposed source model is rarely done. In Figure 8 we compared the teleseismic velocity records with the synthetics generated with our preferred model. In this calculation the $1 \mathrm{D}$ central Taiwan layered model (Table 1) is used to generate the source excitation. An attenuation factor, expressed as a $t^{*}$ of $1 \mathrm{~s}$, is used for $P$ waves, and a 4-s factor is used for $\mathrm{SH}$ waves [Langston and Helmberger, 1975]. The agreement between synthetics and data is remarkable, considering we simply assume the stations are sited on a half-space Earth. In fact, some of the disagreements, such as the mismatch to the anomalous long-period tail of the $P$ waveform at station TIXI in the range from 40 to $60 \mathrm{~s}$ (Figure 8 ), are more likely caused by the receiver site effect 

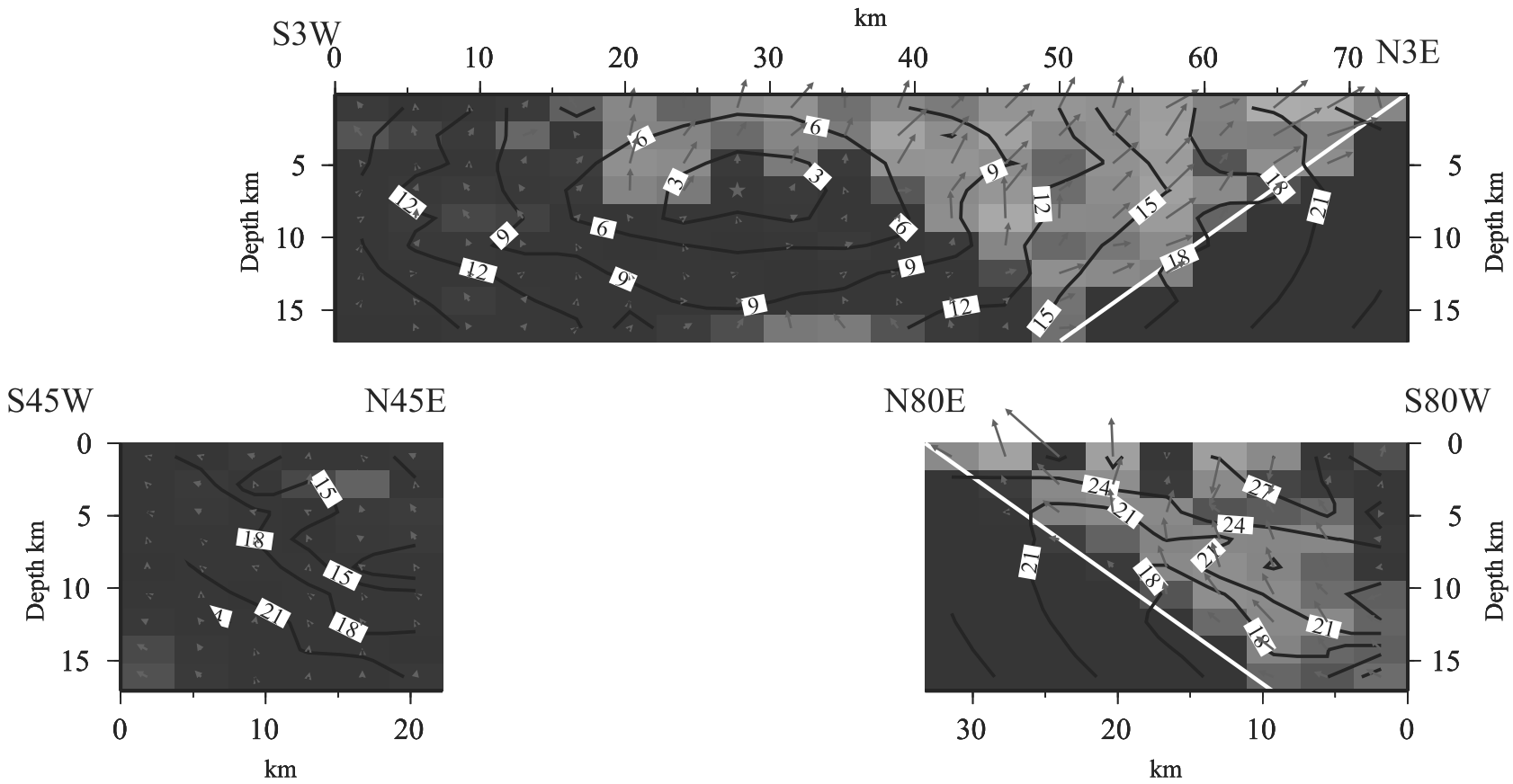

Slip distribution (Azimuth E20S, Elevation 18)

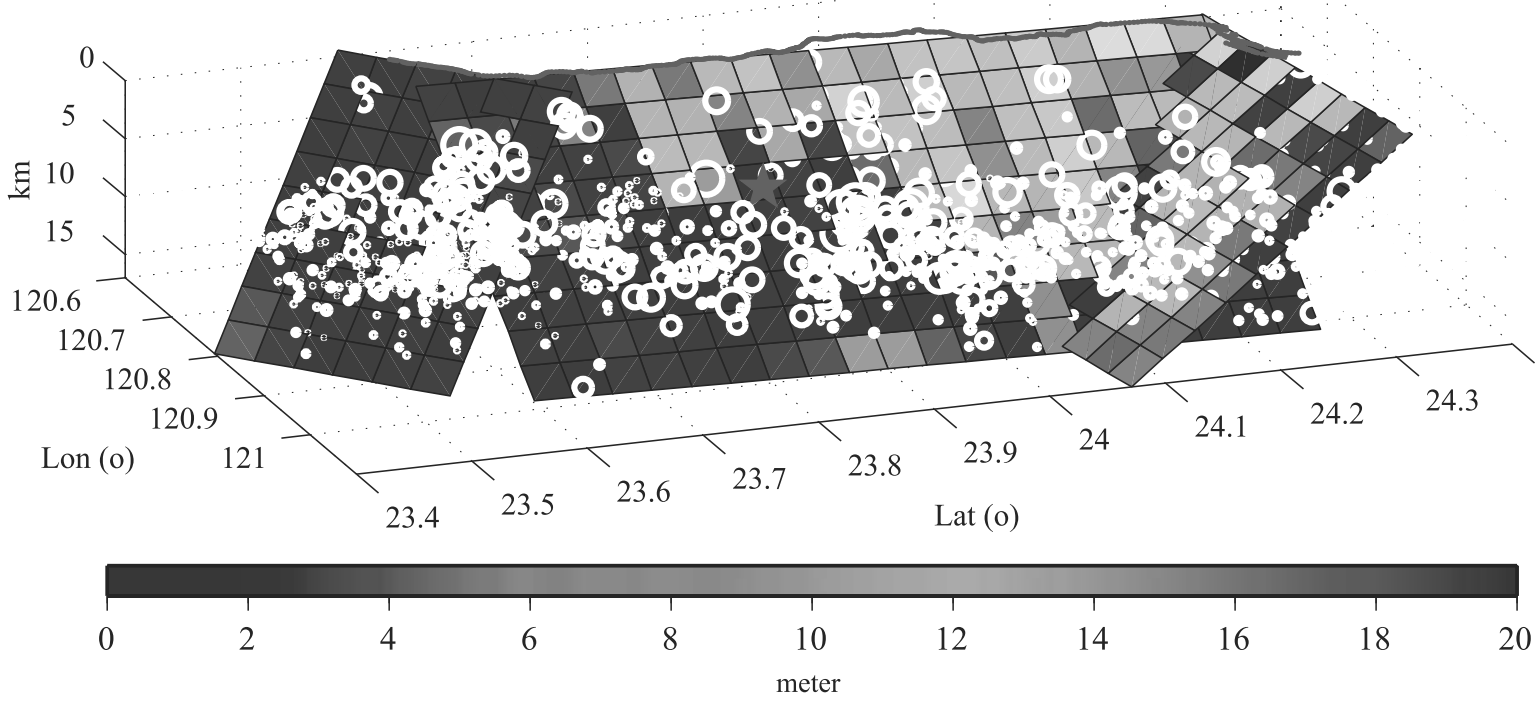

Figure 4. $2 \mathrm{D}$ and $3 \mathrm{D}$ views of the preferred combined inverse model. (top) The slip distribution in a planar view. Fault 1 is on the top, and fault 2 and fault 3 are on the lower-right and lower-left portions, respectively (Figure 2). Fault 1 and fault 2 cross each other, and the white line on the fault planes indicates the intersection. The color bar shows the amount of slip, the arrows indicate the slip vectors, and the contours display the rupture initiation time. (bottom) 3D view of the same slip distribution. See color version of this figure at back of this issue.

than by the source excitation because we cannot find the corresponding phase in other records.

\section{Rupture Kinematics}

[18] In section 4 we discussed the waveform fits of our preferred model against the observations. In this section we address the kinematics of the source description and its relationship to fault roughness and surface breakage. As introduced earlier in Figure 4, we display the slip distribution along with rupture front contours indicating the initiation of rupture. We can estimate the rupture velocity by dividing the on-fault hypocenter distance by the rupture initiation time and averaging over the subfault elements. Since the timing on subfaults with large slip is determined better than on those with small slip, we can weight them averaged by slip offsets, using the values in Figure 4 to obtain an average rupture velocity of $2.0 \mathrm{~km} \mathrm{~s}^{-1}$. The 


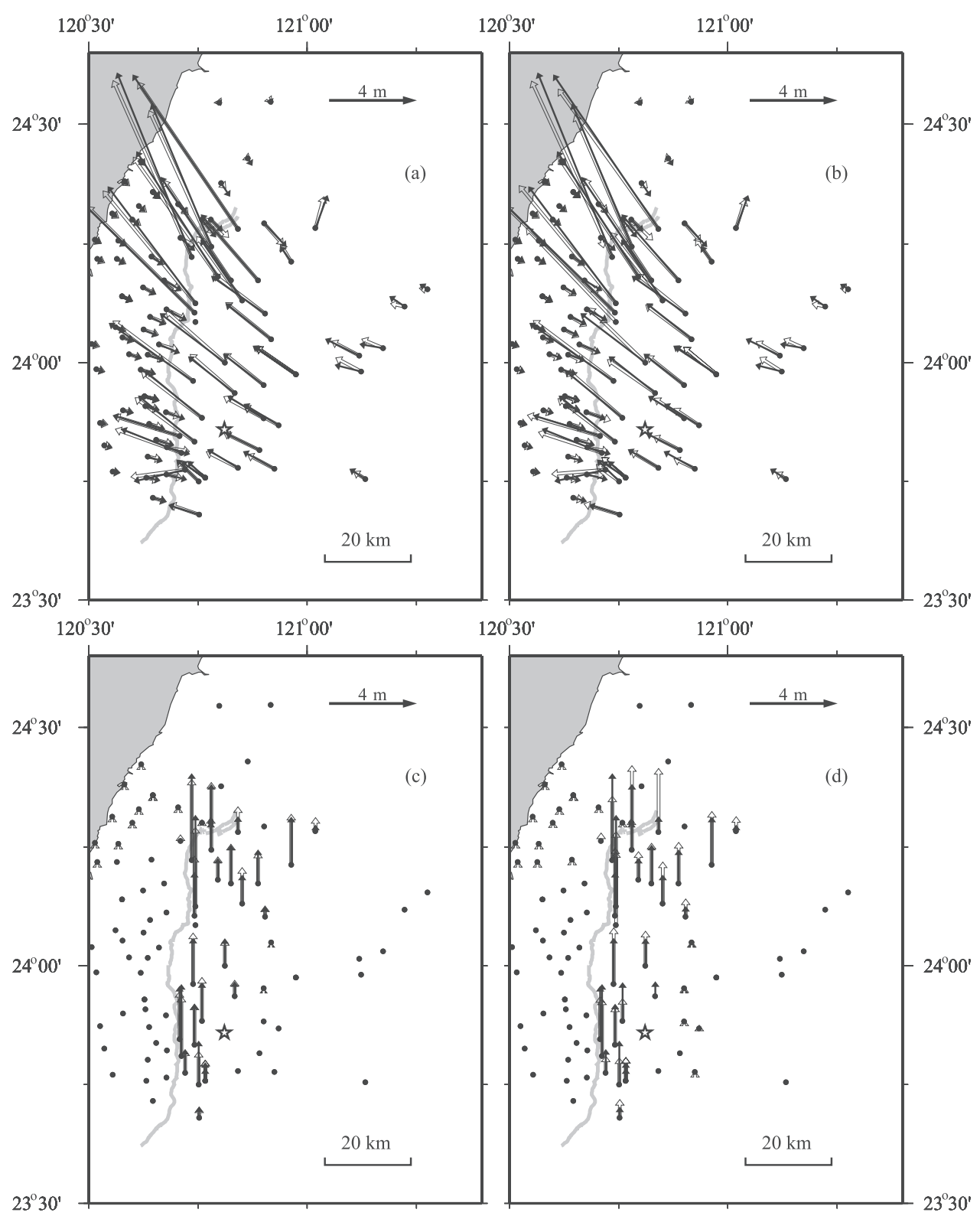

Figure 5. Comparison of GPS observations and synthetic static displacements generated by the slip models constrained by (a and c) static data only or by (b and d) static and strong motion together. The black arrows show GPS vectors and the open arrows show the synthetic values. The shaded lines indicate the surface break. The comparisons of horizontal motions are shown in Figures $5 \mathrm{a}$ and $5 \mathrm{~b}$, and those of vertical motions are plotted in Figures $5 \mathrm{c}$ and $5 \mathrm{~d}$.

advantage of this procedure is discussed by Ji et al. [2002a], although it obscures the faulting roughness.

[19] In Figure 9 we present the model again but in a snapshot form, showing the amount of slip occurring in time windows. Thus the region surrounded by the inner 3-s contour slipped $\sim 1 \mathrm{~m}$ in the first $3 \mathrm{~s}$ and continued to slip at about this level until $\sim 12 \mathrm{~s}$ when it stopped, reaching a total slip of $\sim 4 \mathrm{~m}$, consistent with Figure 4 . In contrast, the region approaching the fault 1 and 2 intersection moved $\sim 8 \mathrm{~m}$ in the 24 - to $27-\mathrm{s}$ interval alone. It is noteworthy that there is a trade-off between rupture initiation time and starting-phase time $\left(t_{s}\right)$. A larger rupture initiation time combined with a smaller starting-phase time $\left(t_{s}\right)$ can generate a compatible response with the combination of a smaller rupture initiation time and a larger $t_{s}$. In contrast, the slip during a finite time interval, as presented in Figure 9, is directly related to the seismic waveforms and therefore should be more robust. It is also noteworthy that after $12 \mathrm{~s}$ the northward rupture front could not catch up with the solid contour, corresponding to a constant rupture velocity of $2.1 \mathrm{~km} \mathrm{~s}^{-1}$ (Figure 9). However, several previous results reported a faster average rupture velocity of $\sim 2.5 \mathrm{~km} \mathrm{~s}^{-1}$. Such a discrepancy is significant and will be discussed in Appendix A.

[20] We will address the most important strong-shaking issue first, in section 5.1 on the slip velocity distribution. 
a $E-W$
$N-S$
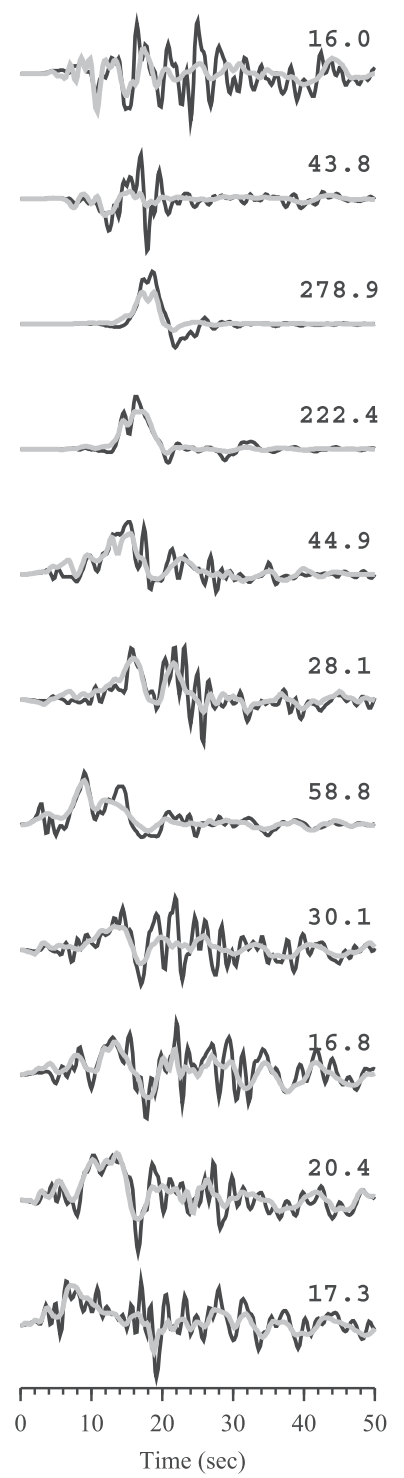

$U-D$
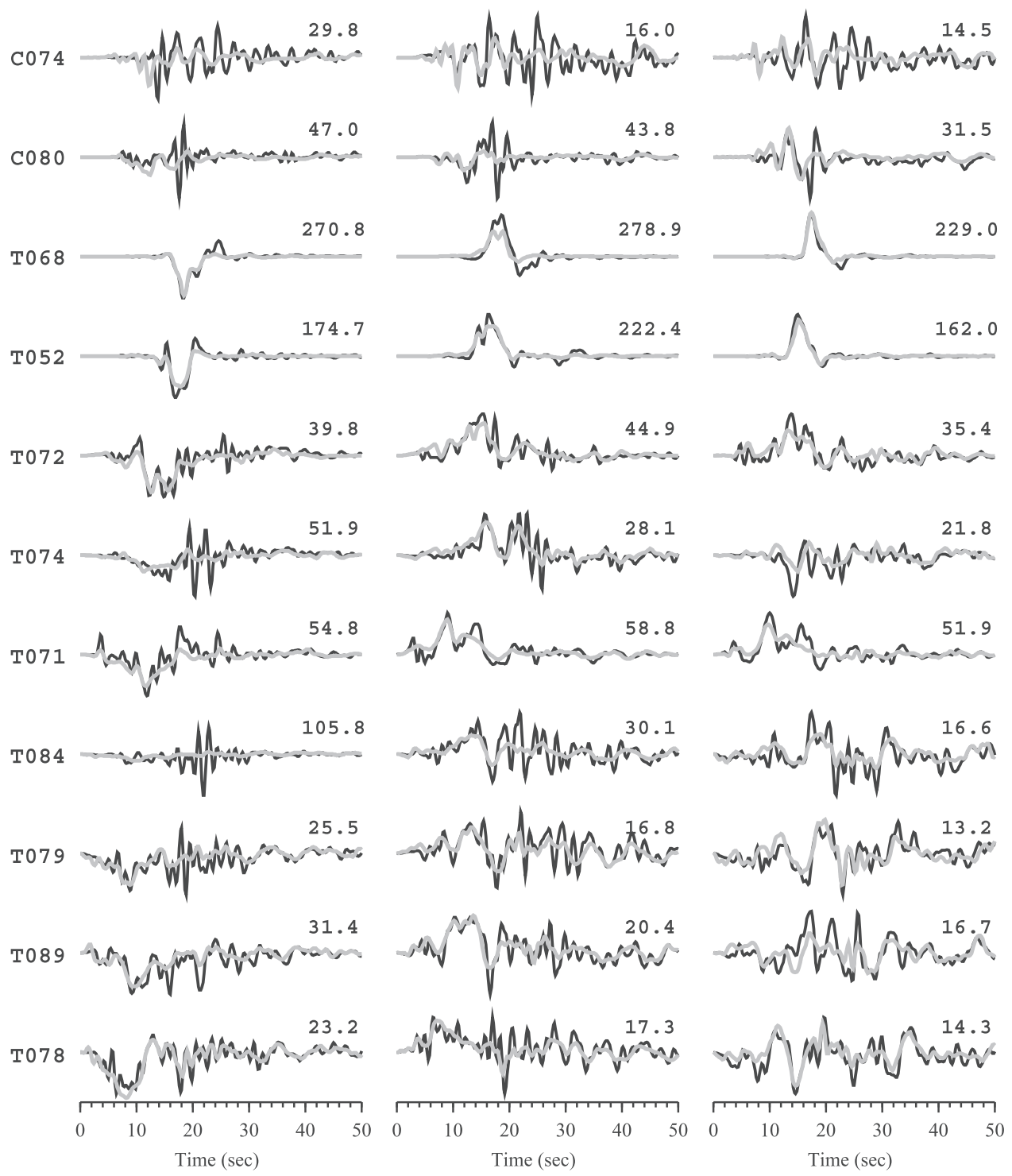

Figure 6. Comparison of strong motion velocity records (bold lines) and synthetic seismograms (shaded lines) generated by the preferred slip model: (a) comparison for the stations in the hanging wall (group 1); (b) comparison for the stations in the footwall (group 2); and (c) comparison for the stations in group 3. Both data and synthetics are aligned by the $P$ arrivals. The number at the end of each trace is the peak velocity $\left(\mathrm{cm} \mathrm{s}^{-1}\right)$ of the data, which has been used to normalize both this record and the corresponding synthetic seismogram.

The roughness in the surface breakage and its relationship to source characteristics are discussed in detail in section 5.2. Then, we will discuss the rupture behavior as it crosses from fault 1 to fault 2 in section 5.3 and the effects of the afterslip and aftershocks in section 5.4.

\subsection{Peak Slip Velocity Distribution}

[21] The sum of $t_{s}$ (starting-phase time) and $t_{e}$ (end-phase time) represents the particle slip duration, or risetime [Heaton, 1990], and is displayed in Figure 10a. The average risetime over the entire Chi-Chi rupture is $7.2 \mathrm{~s}$ (weighting with the slip offsets), which is significantly larger than the values of the previously studied earthquakes (e.g., the 1992 Landers earthquake [Wald and Heaton, 1994] and the 1999
Hector Mine earthquake [ $\mathrm{Ji}$ et al., 2002b]). The ratio of $t_{s}$ and $t_{e}$ is not constant, nor is it entirely uniformly distributed. In Figure $10 \mathrm{~b}$ we show the probability distributions of such ratios in a logarithmic-decimal plot. Note that there is a large peak around 1 and that the average value is 1.3 . Hence, although the slip on some subfaults shows strong evidence that asymmetric slip rate functions are required (e.g., Figure 7), the symmetric one is still the most favorable solution for most of the fault. However, the average ratio may be specific to this earthquake and may not be a general characteristic of large earthquakes.

[22] A particularly interesting result of this study is that the risetime and slip distributions appear to be directly related; that is, the subfaults with a large slip amplitude 
b

$$
E-W
$$

T060

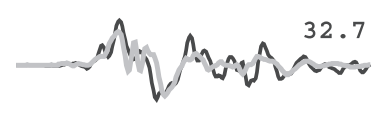

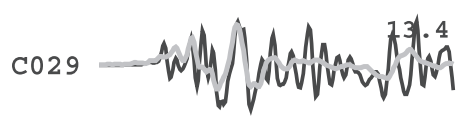
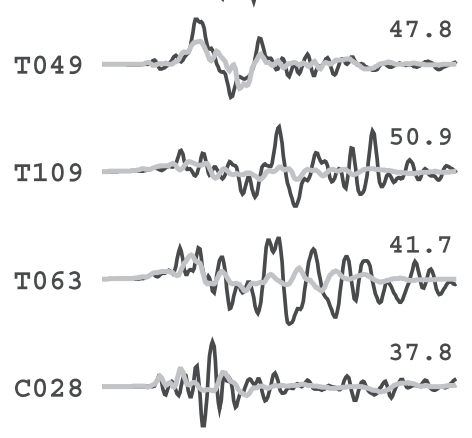

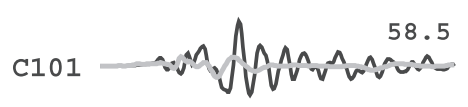

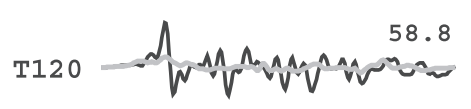

024 Thaी
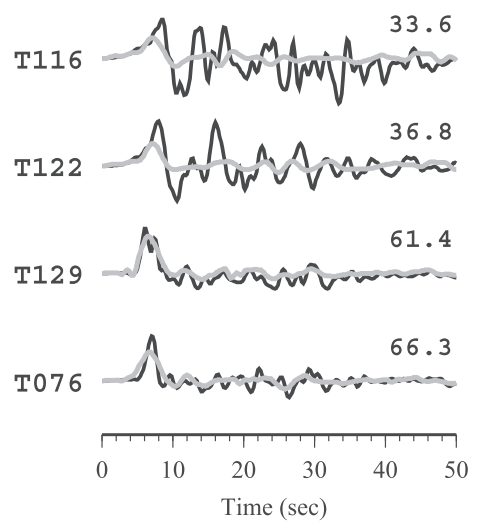

$N-S$
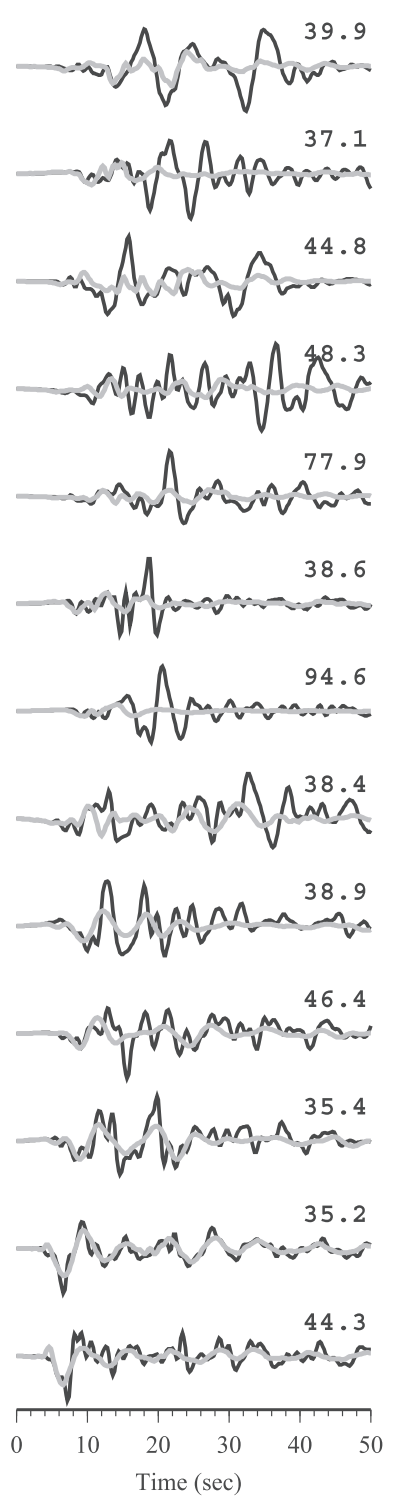

Figure 6. (continued)
$U-D$
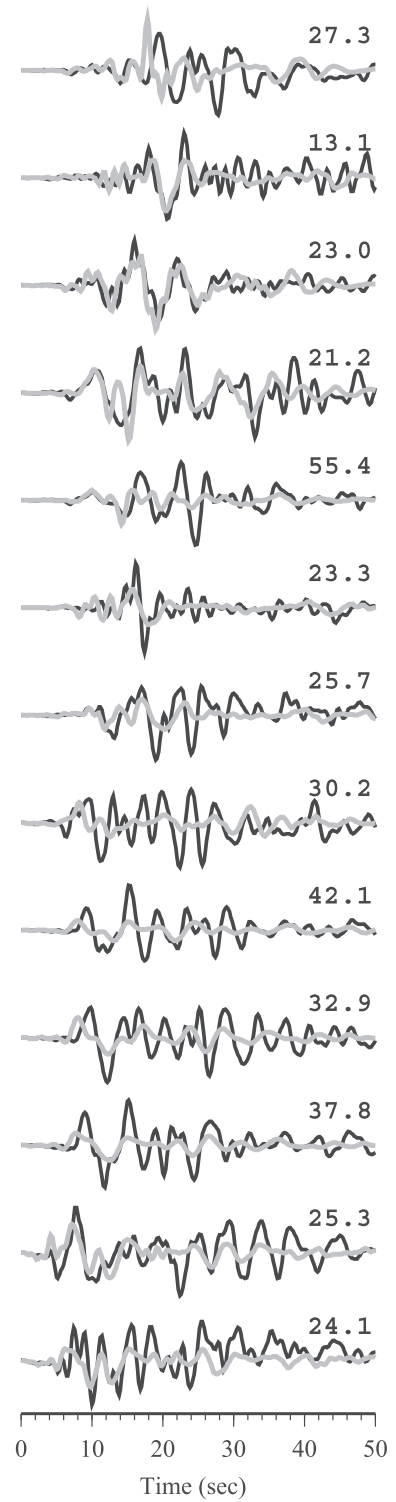

require a long time to slip. To further display this observation, we plot the slip and peak slip velocity distributions in Figures 10c and 10d, respectively. Because of our simple risetime functional form, the peak slip velocities are related directly to Figures $10 \mathrm{a}$ and $10 \mathrm{c}$ by simple division. It is noteworthy that for the large triangular asperity that released most of the seismic moment the slip velocity distribution is apparently much simpler than the corresponding slip and risetime distribution (Figure 10). To first order, the slip velocity increases with the distance related to the southeast boundary of this asperity. The subfaults at this boundary have larger slip amplitudes accompanying longer risetimes than those whose slip velocities are small (in the range of $\left.1 \mathrm{~m} \mathrm{~s}^{-1}\right)$. As the rupture propagates, this value increases to $2 \mathrm{~m} \mathrm{~s}^{-1}$ and reaches over $3 \mathrm{~m} \mathrm{~s}^{-1}$ at the northern tip, where stations T052 and T068 are located.

[23] The dynamic rupture of low-angle thrust faults had been studied with both laboratory experiments and dynamic numerical simulations [e.g., Brune, 1996; Oglesby et al., 1998]. Oglesby et al. [2000] showed that the slip velocity would be amplified significantly in the top few $\mathrm{km}$, which is consistent with our inversion, where the slip velocities on the near-surface subfaults are larger, in general (Figure 10d). Ni et al. [1999] further argued that a dynamic decoupling of the hanging wall from the footwall might occur and that this will prevent the hanging wall motion from radiating to the far field. It simply implies that the far-field radiation energy of the thrust event will be lower than predicted by the dislocation model [Brune, 1996]. However, the favorable forward prediction of the teleseismic body waves (Figure 8) suggests that the difference is small, consistent with the recent numerical simulations of Aagaard et al. [2001].

\subsection{Rupture Propagation on a Rough Fault Plane}

[24] Usually, the surface expressions of thrust faults are much more sinuous than for strike-slip faults (K. Sieh, 
C
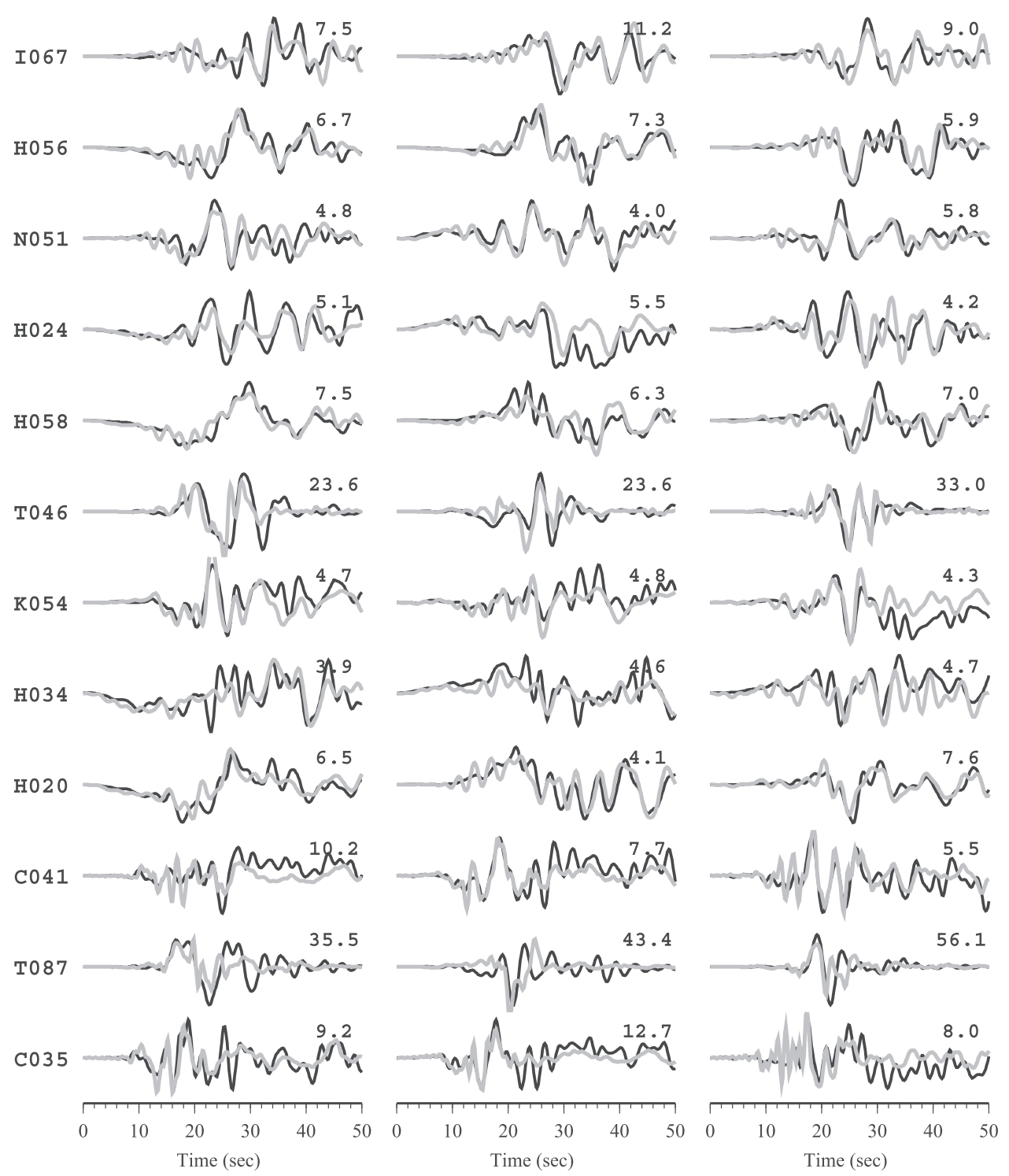

Figure 6. (continued)

personal communication, 2001); this appears true for the Chelungpu fault. In particular, there is a "bulge" [Zeng and Chen, 2001] at $\sim 12-25 \mathrm{~km}$ north of the epicenter, indicated by arrows in Figure 10c. Such a curvature is probably associated with the topography of the ground surface, with the topography of the fault plane, or even with both. In our simple model the curvature and the potential downdip extension (corrugations) are not taken into account. However, the slip distribution seems to show a clear correlation with the shape of the fault trace. In the fault plane east of the hypocenter, there are three low-slip zones extending eastwest (indicated by arrows, Figure 10c). Two of them connect with the beginning and end of the "bulge," and the last one links with the small curve just south of station T052. The downward extension of the low-slip zones suggests that the surface curvature is a deep-seated feature. Even though this argument is only speculation, it is, in fact, consistent with the observation that the adjacent Chunghua and ShuangTung faults have a similar curvature (Figures 2 and 10) to the initial western step located at roughly the same latitude. Furthermore, it seems to be consistent with the following unusual pattern of rupture propagations, as well.

[25] Zeng and Chen [2001] noticed that the rupture slows down when it crosses the above "bulge" and suggested that such geological curvatures acted like a barrier and blocked the northward oblique rupture propagation. This feature also appears in our model and can be observed in Figure 9: When the rupture front meets the northern edge, or right step, of the "bulge," it does not extend during the 12- to 15 -s interval. In contrast, the rupture front crosses the southern side, or left step, without an observable delay. Hence the north side of the "bulge" rather than the south side decelerates the rupture propagation.

[26] Impeding effects of fault topography on the earthquake rupture propagation have been the subject of a number of extensive investigations [e.g., Segall and 


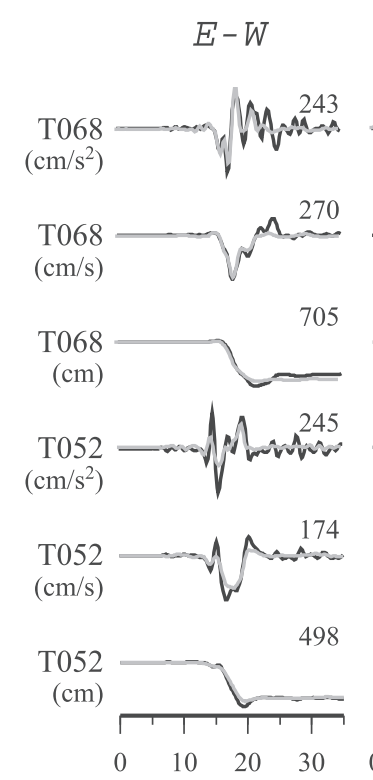

(s)
$N-S$
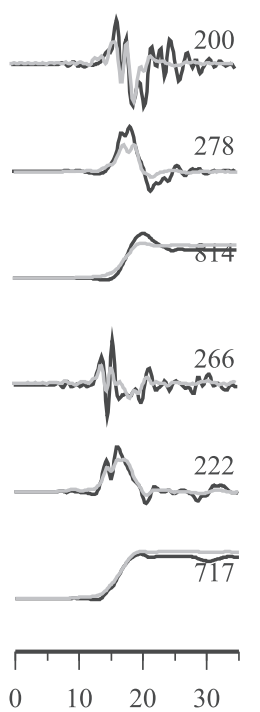

(s)
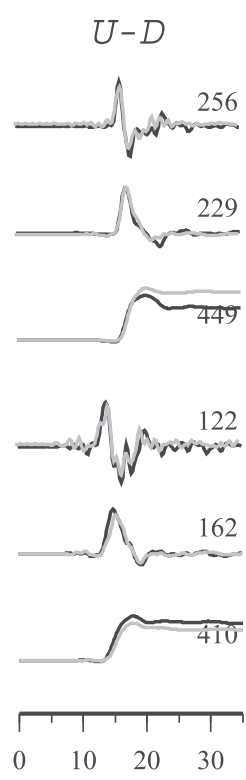

(s)

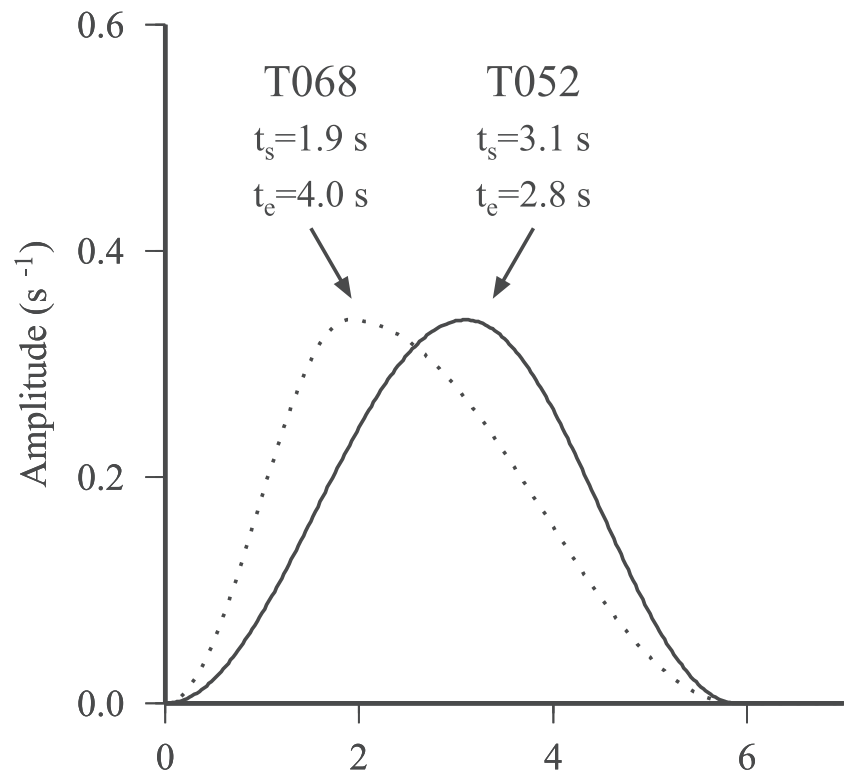

Time (s)

Figure 7. (a) Forward predictions at stations T068 and T052. The displacements, velocities, and accelerations of these two stations are compared with the synthetic predictions. Note that only the velocity records are used in the inversion. (b) The normalized slip-rate functions at the subfaults located beneath these two stations.

Pollard, 1983; Sibson, 1985; Scholz, 1990; Harris and Day, 1999; Magistrale and Day, 1999]. Both quasistatic and numerical simulations indicated that a "step over" similar to those associated with two sides of the "bulge" is an important impediment for the strike-slip motions but is less important for dip slip [e.g., Scholz, 1990; Harris and Day, 1999; Magistrale and Day, 1999]. In the study region we do observe significant left-lateral strike-slip motion concentrated in the top $8 \mathrm{~km}$ (Figure 11). For such left-lateral motions the mechanical effects of the two "step overs" are different, which can be explained schematically with the cartoon in Figure 12. Note that left-lateral motion will kinematically "open" the fault zone between the hanging wall and the footwall at the left step of the "bulge" but "close" it at the right step. Effectively, these represent dilatational and compressional step overs, which reduce the normal stress on the southern boundary but increase it on the northern side, and which change the fault friction and cause the alternative kinematic behaviors shown in Figure 9.

[27] However, the slip on the fault plane in deeper regions $(8-12 \mathrm{~km})$ yields a different scenario. From the snapshots taken at $6-15 \mathrm{~s}$ we note that the rupture front clearly lags in this region compared with both the shallower and deeper rupture (snapshot at 9-12 s, Figure 9). We should point out that such a result is not at odds with the earlier example because the slip direction in this region changes from oblique thrusting to a nearly pure thrust (Figure 11). The variation in slip direction implies that the prestress accumulations are different between this part and the rest of the fault plane. It is noteworthy that in a map view a small cluster of aftershocks southeast of station T071 (Figure 11) is close to the interface separating the two regions with different slip directions, and it is probably related to this feature, even though their precise hypocentral depths are not known. A careful analysis of the aftershock cluster could probably shed new light on this interesting puzzle.

\subsection{Intersection Between Fault 1 and Fault 2}

[28] The previous static inversion (Part I) indicated that these two fault planes form the surface of a "wedgeshaped" block. The coseismic slip was limited to its surface. Because the rupture direction changed roughly $90^{\circ}$ across the hinge line, the intersection of these two planes, or the "hinge line" of the block, seems to be an important barrier to the propagation of the dynamic rupture. Unfortunately, our resolution around this intersection is limited because of the absence of strong motion stations directly above. For this reason we can use a rather sharp intersection here, even though it is more physically plausible to assume that the "hinge line" is a narrow transition zone.

[29] However, the overall kinematics characteristics of rupture near the hinge line are fairly well determined. The rupture front reaches the bottom of the hinge line first and then arrives near the surface portions $\sim 6$ s later (Figures 4 and 9). There are no significant delays observed when the rupture crosses the intersection (Figure 10). In fact, the rupture is slightly faster than the average value, as indicated by the snapshots at $15-18 \mathrm{~s}$ and at $18-21 \mathrm{~s}$ seen in Figure 9. The variation of slip velocity around the "hinge line" is relatively complex. Velocities are extremely large on some deep subfaults, which is possibly related to the rupture initiation of the transition zone because the rupture of the hinge line starts at the bottom. For the slip in the intermediate-depth range $(4-10 \mathrm{~km})$ the hinge line separates the region in fault 1 with $>2 \mathrm{~m} \mathrm{~s}^{-1}$ slip velocity from the region in fault 2 with $<2 \mathrm{~m} \mathrm{~s}^{-1}$. 
a<smiles>[R19][R3]([H])([H])[H]</smiles>

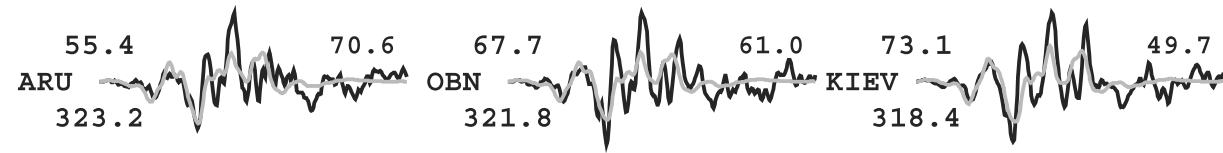

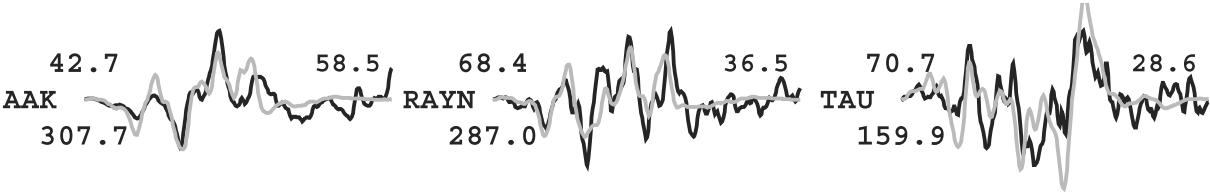

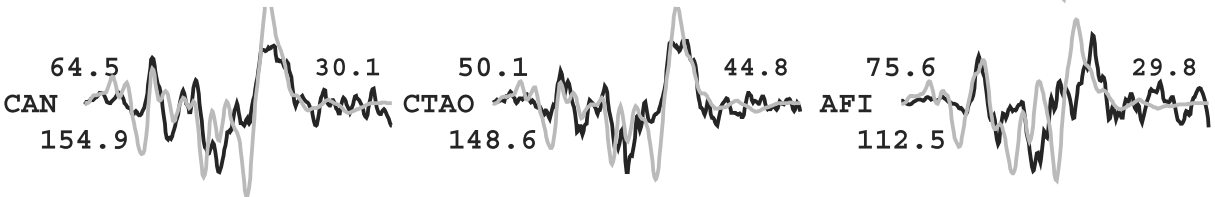

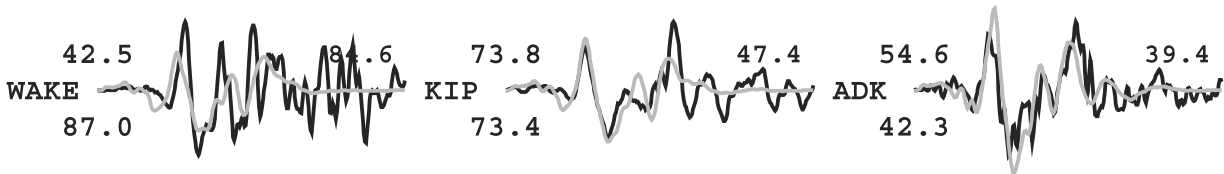

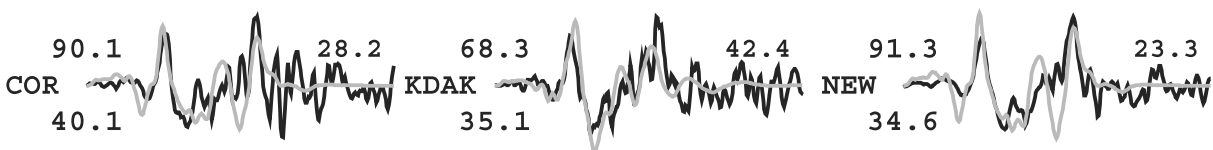

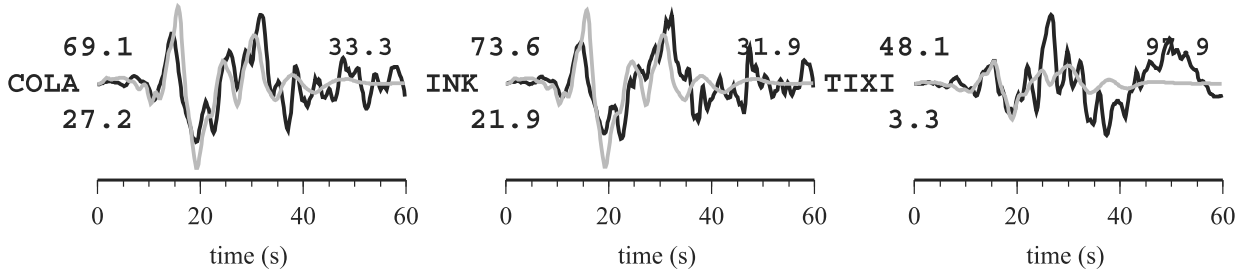

Figure 8. Comparison of teleseismic velocity records and synthetic seismograms predicted by the preferred slip model: (a) comparison of $P$ waves and (b) comparison of $S H$ waves. Both data and synthetics are aligned by the $P$ or $S H$ arrival, respectively. The number at the end of each trace is the peak velocity of data in $\mu \mathrm{s}^{-1}$, which has been used to normalize both this record and the corresponding synthetic seismogram. The number above the station name is the epicentral distance, and below it is the azimuth.

[30] There are two interesting questions related to the rupture near the intersection. First, the initiation time of the rupture does not have a large delay when traversing the intersection, even though the rupture propagation direction has changed by $\sim 90^{\circ}$. Because of the existence of large strike-slip motions in the side of fault 1 (Figure 11), it seems to be a contradictory example of our previous quasistatic explanation; that is, compressional step over does not slow down the rupture. Second, for the strike-slip motion the hanging wall associated with fault 1 extends to the north (left lateral); the favorable motion direction of the hanging wall of fault 2 seems to be east (left lateral) instead of west (right lateral).

[31] However, this intersection is different from those related to the "bulge" structure. It is not normal to the fault strike, as in the previous situation. Instead, the "hinge line" is a slant. It has a rake of $55^{\circ}$ relative to fault 1 and a rake of $125^{\circ}$ relative to fault 2 (Figure 13a). The slant intersection thus has different mechanical effects compared to vertical ones, which can be easily understood with the two simple cartoons in Figure 13b. Suppose there are two dip faults with the same dip angle. One fault is bounded with a vertical intersection at its right side (case 1), while the other is bounded with a slanting one (case 2), as shown in Figure 13b. We use black lines and shaded lines to represent the position of footwalls and hanging walls before the occurrence of an earthquake, respectively. If pure thrust motions occur on these two faults and, consequently, the hanging walls move to the positions indicated by dotted lines when we use the footwalls as references, then the intersection of the hanging walls will laterally separate from that footwall in case 2 but keep close in case 1 (Figure 13b). 
$\mathrm{b}$

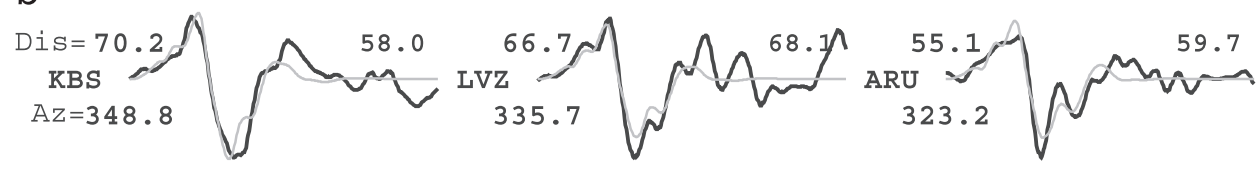

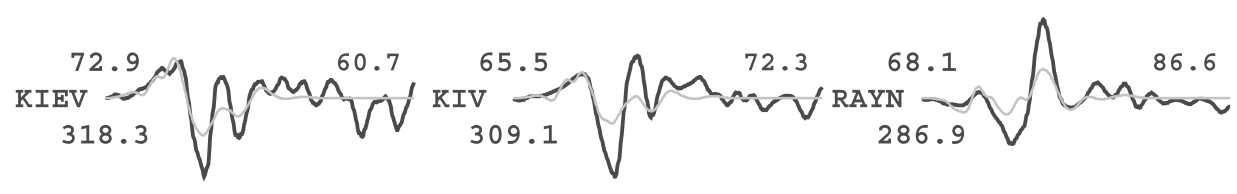

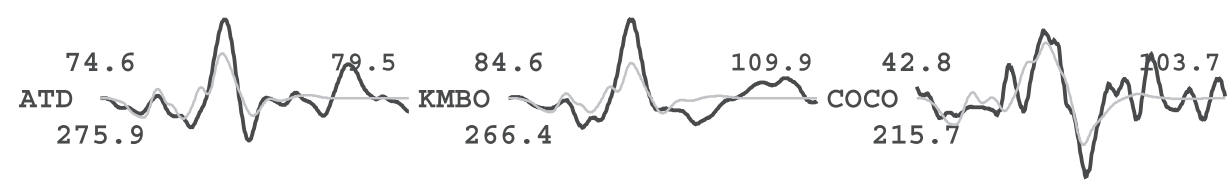

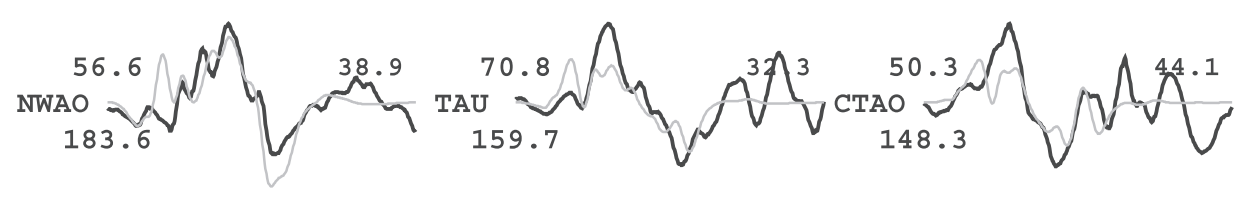

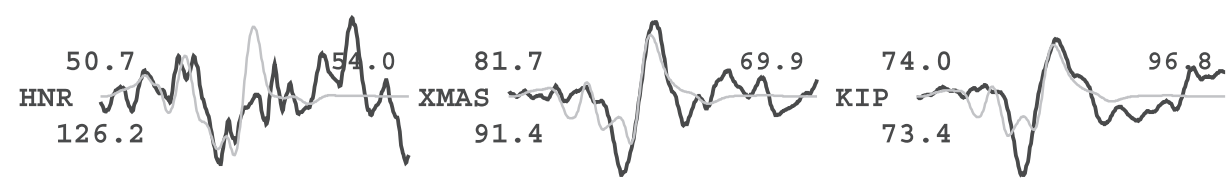

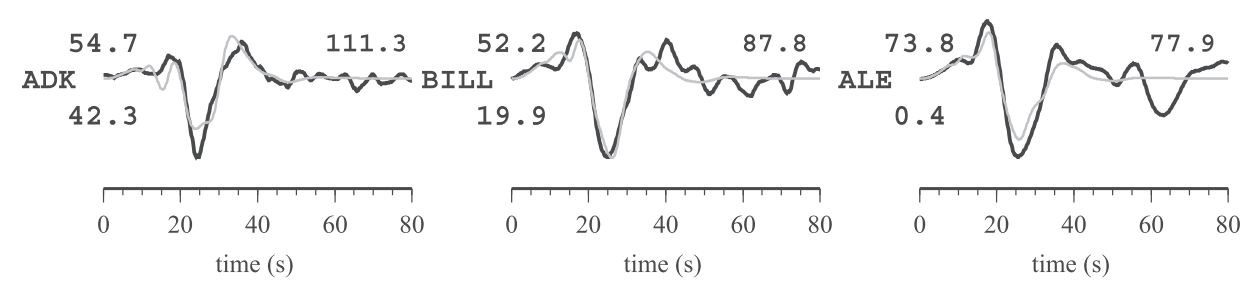

Figure 8. (continued)

This observation generates the insight to explain the above two questions. First, strike-slip motions are expected to occur around a slant intersection, which is consistent with the pattern in fault 1 , where the strike-slip components on the subfaults next to the intersection are significantly larger than others (Figure 11). Furthermore, it is not difficult to imagine that the strike-slip motion favored by this mechanism should be right-lateral related to fault 2. Second, the strike-slip motions apparently fill the mechanical "gap" associated with the thrust motions, so the aforementioned "closing" effect at the "compressional step over" is reduced. Thus this intersection should not be a strong impediment.

[32] Even though, to our knowledge, a dynamic simulation with such a slant intersection has never been studied, the observation agrees well with the idealized thrust/tear fault system modeled dynamically by Magistrale and Day [1999]. Their simulation demonstrated that the vertical intersection is not an important barrier for the propagation of pure thrust rupture, which is, in essence, because the slip vector is approximately parallel to the line of intersection of the fault planes [Magistrale and Day, 1999]. This is consistent with the cartoon shown in Figure 13b; that is, if the slip direction of case 2 is parallel to the fault intersection, no "gap" could be formed. In our rupture model, slip vectors of subfaults around the intersection are, in fact, nearly parallel to the intersection, consistent with this alternate interpretation (Figure 4).

[33] While a slant intersection is, apparently, an efficient geometry for rupture propagation, how such a geometry formed presents an interesting question. Unfortunately, we cannot address it without more geological observations. However, the accumulated effect of this earthquake shows good agreement with the local stress field. Our previous static inversion (Table 2 in Part I) indicated that even though the slips on both fault 1 and fault 2 have important strikeslip components, the tensor sum of coseismic slip was in good agreement with the nearly pure thrust focal mechanism solution of the Harvard centroid moment tensor (CMT). The derived maximum compressional axis has an azimuth of $\mathrm{N} 303^{\circ} \mathrm{E}$, nearly identical to the CMT solution $\left(\mathrm{N} 304^{\circ} \mathrm{E}\right)$, which matches the trend of local compressional stress direction obtained by analyzing geological and geophysical data $\left(\mathrm{N} 302^{\circ} \pm 20^{\circ} \mathrm{E}[\mathrm{Hu}\right.$ et al., 1996]). The 

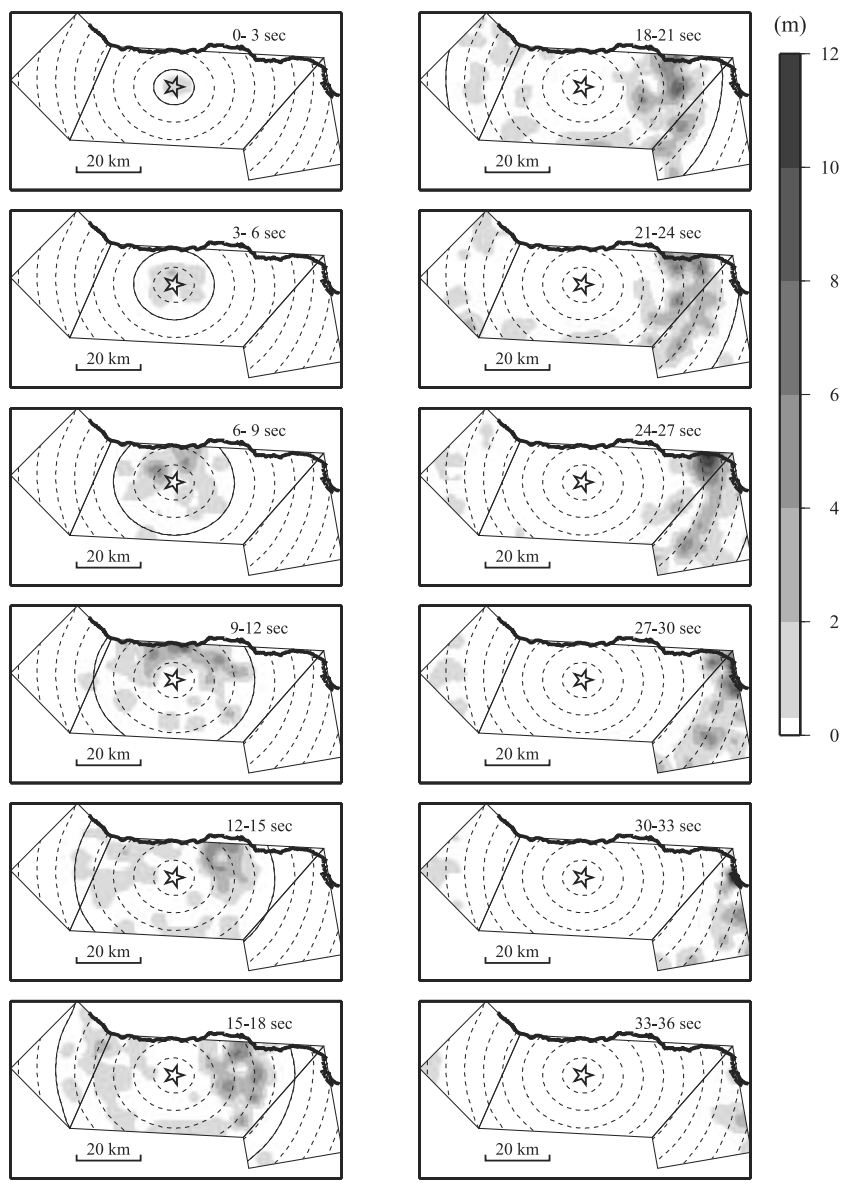

Figure 9. Snapshots of the 1999 Chi-Chi earthquake source rupture at every $3 \mathrm{~s}$. The numbers at the upper right corner of each panel indicate the time interval of this snapshot. A color bar shows the amount of slip during this period. A red star indicates the location of the hypocenter, and the red lines show the surface trace. Note that the dashed contours show the positions of the rupture fronts with a speed of $2.1 \mathrm{~km} \mathrm{~s}^{-1}$ every $3 \mathrm{~s}$, and a solid contour specifies the rupture front with the same speed at the end of each snapshot. See color version of this figure at back of this issue.

direction is also close to the $\mathrm{N} 305^{\circ} \mathrm{E}$ plate convergence azimuth [Seno et al., 1993]. The tensor summation is a robust result and does not change in our current model. Such good agreements suggest that the far-field tectonic loading of the 1999 Chi-Chi earthquake may be a compressional force along the plate convergence direction. Because the strikes of fault 1 (Chelungpu fault) and fault 2 are both oblique to the plate convergence direction, if the stress field associated with the Chi-Chi earthquake acts as suggested, the prestresses associated with the left-lateral and rightlateral strike-slip motions are expected to accumulate on fault 1 and fault 2, respectively, hence the fact that the Chi-Chi rupture involving two fault planes is likely due to tectonic loading and that the occurrence of the Chi-Chi earthquake reflects the "wedge-shaped" block motion pushed by the local tectonic stress field (Part I).

\subsection{Effect of Afterslip}

[34] In this study we invert for the slip history of the Chi-Chi event by fitting both seismic and static data simultaneously. However, such a result may not be the solution closest to the real rupture, particularly when the data contain significant afterslip noise. Since the GPS measurements of the Chi-Chi main shock included the effects of some aftershocks and aseismic afterslip [Yu et al., 2001], additional slip should be expected to be included in the inversion results to match the GPS measurements. However, the strong motion data only include the effects of coseismic slip during first minute after the rupture initiation. The only way to improve the fit to the GPS measurement without a large degradation of the fit to the seismic data is to increase the slip and slip duration simultaneously. During this study we find an example of such inverted artifact in the region where large afterslip might be expected.

[35] In a map view the biggest aftershock cluster shown in Figure 10c is located roughly east of the hypocenter. This cluster has two $M_{w}>6$ aftershocks, which are included in the epoch-surveyed static measurements [Yu et al., 2001]. The source parameters of these two events have been determined independently [e.g., Kao and Chen, 2000]. One event (22 September 1999) had a moment magnitude of 6.2 but was $29 \pm 3 \mathrm{~km}$ deep; another event (25 September 1999) was the largest aftershock of the Chi-Chi event, had a magnitude of 6.4, and was $15 \pm 4 \mathrm{~km}$ deep [Kao and Chen, 2000]. Thus the latter one generated most of the static effect that was predicted to be $10 \mathrm{~s}$ of $\mathrm{cm}$. In our inverted model, there is a small asperity composed of four subfaults at the bottom of fault $1(\sim 15-17 \mathrm{~km}$, Figure 4$)$, which is close to the aforementioned aftershock cluster (Figure 10). The seismic moment of the four subfaults is equivalent to an earthquake with a moment magnitude of 6.6, slightly larger than that of the biggest aftershock. Finally, all subfaults of this asperity have the longest risetime permitted in our inverted procedure, and they then have very small contributions to the velocity strong motion waveforms. Hence this is probably just a recovery to the postseismic slip (a large aftershock), where the static signal necessary to fit the "contaminated" geodetic data is given a sufficiently long risetime to avoid misfitting the seismic waveforms.

Figure 10. (opposite) Map views of the rupture characteristics of the preferred model. Only the subfaults with $>1 \mathrm{~m}$ slip ( $5 \%$ of the peak slip) are displayed because the risetime of subfaults with weaker slip is hard to constrain reliably. Red lines show the surface break and black lines show adjacent major faults named ChungHua, Chelungpu, ShuangTung, and LiShan from west to east, respectively. The pink triangles show near-fault strong motion stations. (a) Risetime distribution on the base map of local topography. The color bar shows the risetime values. (b) Distribution of the $t_{s} / t_{e}$ ratios. (c) Slip distribution. The color bar shows the slip offsets. The aftershocks are plotted in circles whose sizes are proportional to the $M_{L}$ of the events. There are three low-slip zones on fault 1, indicated by red arrows. Note the aftershock cluster east of the hypocenter (region A) and the small cluster south of station T071 (see the text). (d) Slip velocity distribution. The color bar shows the peak slip velocity. See color version of this figure at back of this issue. 

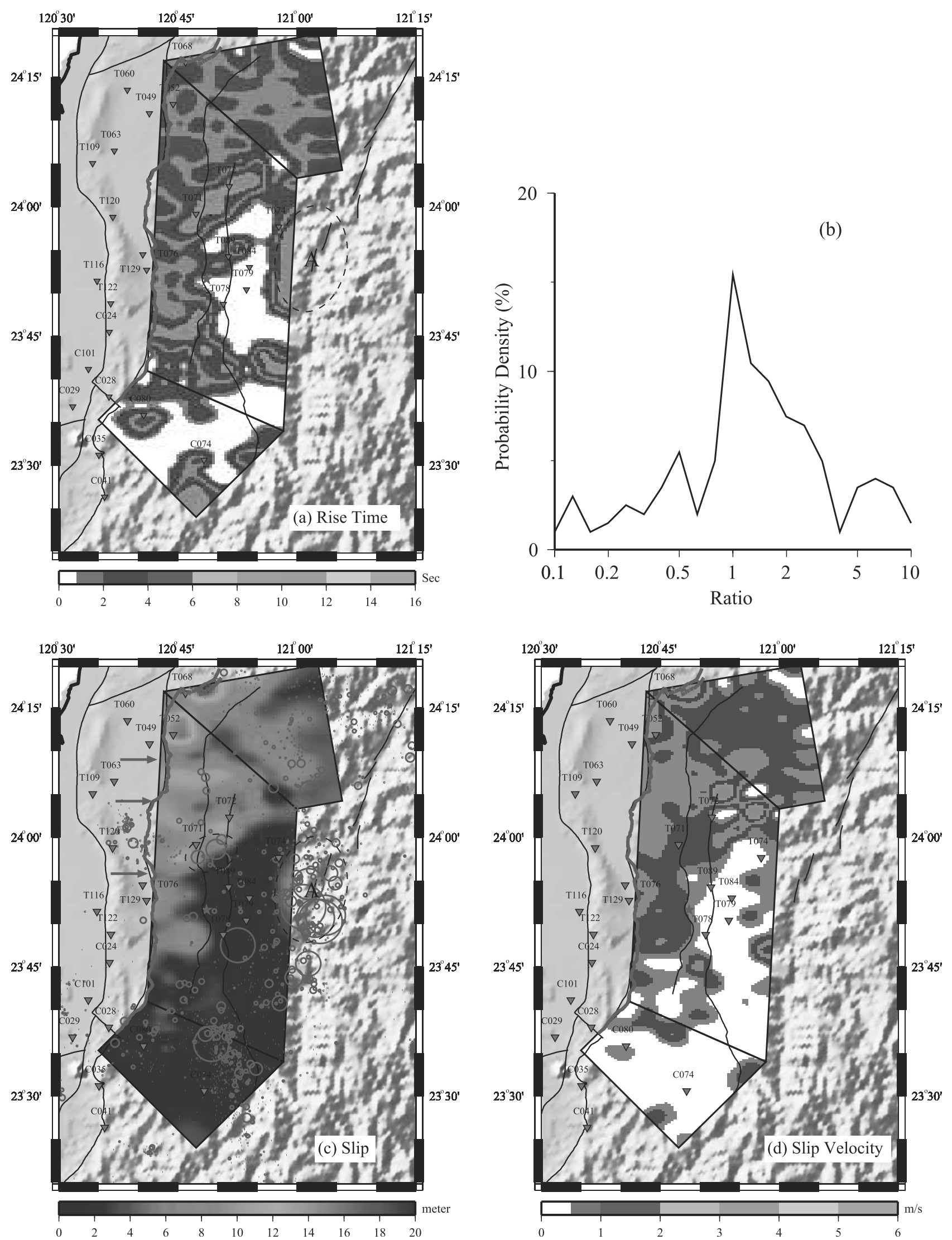

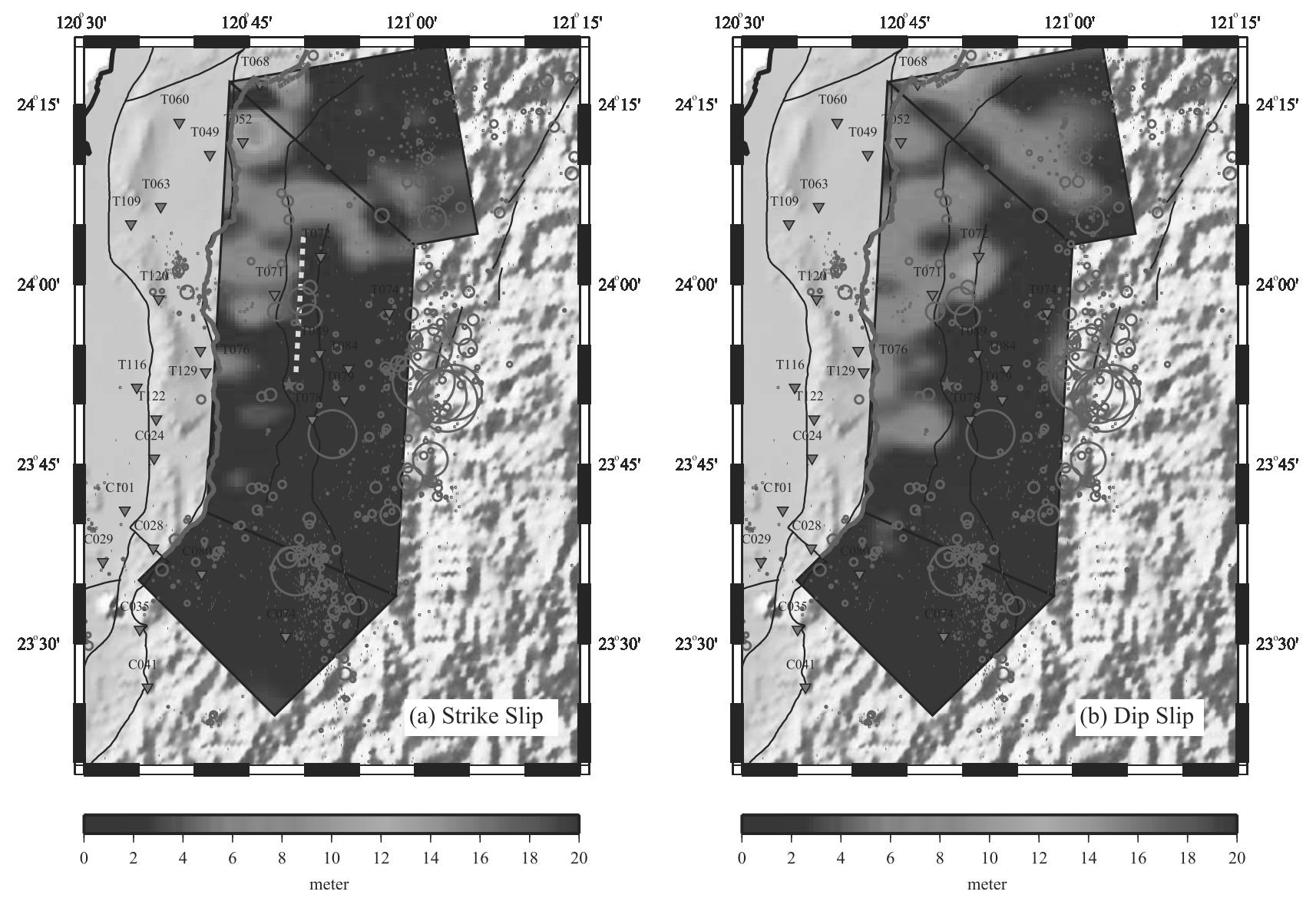

Figure 11. Slip decomposition. The oblique motion of the Chi-Chi earthquake is separated into (a) strike-slip and (b) dip-slip components. The color bar shows slip amplitudes, and circles indicate the aftershocks. A yellow dashed line shows the surface projection of an isodepth line of $8 \mathrm{~km}$ on the Chelungpu fault. Note that the amplitudes of strike-slip motions are comparable with those of the dip-slip motions, and the strike-slip motions on fault 1 around the "bulge" of the surface break are shallower than $8 \mathrm{~km}$. See color version of this figure at back of this issue.

[36] Fortunately, on most of the fault surface with large slip, significant aftershocks are absent. The continuous GPS measurements also suggested trivial afterslip in the northern portion of the Chi-Chi rupture plane [Yu et al., 2001]. Therefore it is probably safe to constrain the slip model with both GPS and seismic data, even though the interpretation of the results must be handled carefully.

\section{Conclusions}

[37] We have inverted both strong motion records and GPS data to generate the rupture characteristics of the 1999 Chi-Chi earthquake using the inversion procedure developed by Ji et al. [2001]. Three-plane fault geometry constrained by the static-only inversion [Ji et al., 2001] is applied to investigate the kinematic rupture characteristics using 119 three-component GPS measurements and 108 velocity seismograms.

[38] We find that there is no difficulty in explaining the strong motion data with this new fault geometry. In addition, the inverted fault model can explain the independent teleseismic $P$ and $S H$ velocity waveforms quite well. The total seismic moment of the Chi-Chi earthquake is
$2.7 \times 10^{20} \mathrm{~N} \mathrm{~m}$, in agreement with the seismic moment estimates of Harvard [Dziewonski et al., 2000] and the U.S. Geological Survey [Sipkin et al., 2000]. Most of the moment is released in a big triangular-shaped asperity beginning $12 \mathrm{~km}$ north of the hypocenter and involving both fault segments 1 and 2. After analyzing the slip distribution and rupture evolution we find that the complex rupture history during the Chi-Chi earthquake has the following relations with the fault geometry.

[39] 1. The occurrence of the 1999 Chi-Chi earthquake reflects the motion of a "wedge-shaped" block driven by local tectonic stress. Because the trend of the current compressional stress direction is not normal to the preexisting weak zone, the Chelungpu fault and the unnamed fault segment (fault 2), the strike-slip motion makes an important contribution on both fault 1 and fault 2 , even though the tensor summation of them is nearly pure thrust.

[40] 2. The slip distribution implies that the jog in the fault trace of the Chelungpu fault is a deep-seated feature, or corrugation. The northward propagation of the oblique slip significantly delays at a compressional "step over."

[41] 3. The intersection between the Chelungpu fault (fault 1) and fault 2 does not display a delay in rupture 


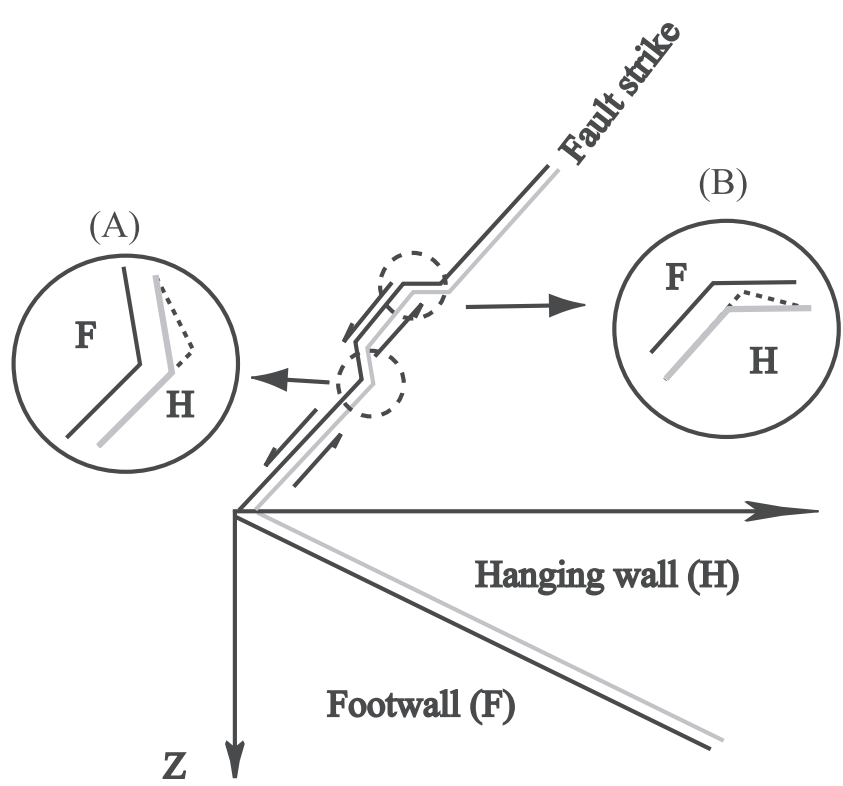

Figure 12. Mechanical effect of a fault "step over." The 3D cartoon displays the mechanical effects of the fault "bulge" in the Chelungpu fault. The black lines represent the footwall fault surface $(\mathrm{F})$. The shaded lines indicate the position of hanging wall surface $(\mathrm{H})$ before the Chi-Chi earthquake. The mechanical effects at two sides of the fault "bulge" are blown up in inset a and inset b, where the dashed line represents the hanging wall position relative to the footwall during the fault rupture. Note that the leftlateral strike motion causes the hanging wall to move close to the footwall at the north "step over" but to separate from it at the south "step over." See text for details.

and apparently does not act as a "barrier." This result is also consistent with the particular fault geometry around this intersection.

[42] 4. The peak slip velocity near the free surface is larger in general, as predicted by physical experiments [Brune, 1996] and by dynamic simulations [e.g., Oglesby et al., 1998].

\section{Appendix A: Average Rupture Velocity of the 1999 Chi-Chi Earthquake}

[43] Rupture velocity is a very important parameter in studies involving earthquake dynamics. For instance, there are analytic relationships between the rupture velocity and the ratio of the fracture energy to seismic energy [Kostrov, 1966; Fossum and Freund, 1975]. Because the rupture velocities for many previously modeled large shallow earthquakes were $\sim 75-85 \%$ of shear velocities [Heaton, 1990], Kanamori and Heaton [2000] have argued that the fracture energy is only a small portion of seismic energy and can be neglected in discussing the energy budgets of large, shallow earthquakes. However, the recent study of the 1999 Hector Mine earthquake showed an exception, where the average rupture velocity was only $\sim 1.9 \mathrm{~km} \mathrm{~s}^{-1}$, or $55 \%$ of the shear wave speed [Ji et al., 2002b; Kaverina et al., 2002]. Since our results for the Chi-Chi earthquake are, again, lower than other estimations, we will briefly review some of the other studies of this event to establish what may cause these differences.

[44] Several different approaches have been used to estimate the rupture velocity of the 1999 Chi-Chi earthquake. Y. Yagi and M. Kikuchi (Spatiotempoal distribution of source rupture process for 1999 Chi-Chi, Taiwan, earthquake, 2000, http://wwweic.eri.u-tokyo.ac.jp/yuji/taiwan/ taiwan.html) reported the first slip distribution of this event, using a maximum rupture velocity of $2.5 \mathrm{~km} \mathrm{~s}^{-1}$ to model the teleseismic data. With the same data set but with an empirical Green's function approach, Ma et al. [2000] reported that the distribution of rupture velocity is very heterogeneous and varies from 1.6 to $4.0 \mathrm{~km} \mathrm{~s}^{-1}$, with the average around $2.5 \mathrm{~km} \mathrm{~s}^{-1}$, which seems to be confirmed by the finite fault studies preformed by Wu et al. [2001], Chi et al. [2001], and Zeng and Chen [2001].

[45] In the methods used by Y. Yagi and M. Kikuchi, Ma et al. [2001], Wu et al. [2001], and Chi et al. [2001], the Green's function of each subfault is precalculated with a constant rupture velocity, which is assumed to be larger than the maximum true velocity. The slip-rate function, or the derivative of the risetime function of each subfault, is modeled by multiple time windows. If the real rupture velocity is slower than the default one, the slip will occur at later time windows. However, if trivial slip occurs in the default time window, it would not affect the waveform fitting much but may contaminate the estimation of rupture velocity significantly. Furthermore, the rupture initiation time of each subfault does not vary continuously. Instead,
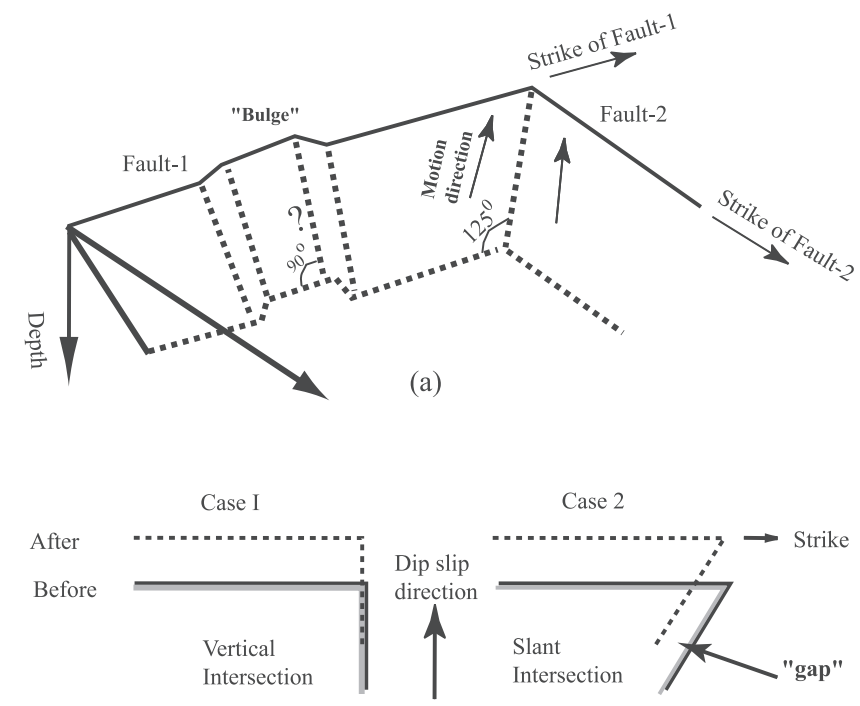

(b)

Figure 13. Effect of the intersection of fault 1 and fault 2 . (a) 3D cartoon representing the footwall of two major fault segments of the Chi-Chi event. Note that the intersection is oblique to the strikes of both fault 1 and fault 2. (b) Mechanical difference between the vertical (case 1, "step over" of the fault "bulge," Figure 12) and slant (case 2, intersection of fault 1 and fault 2) intersections for a pure thrust motion. The black lines show the footwall. The shaded and dotted lines represent the hanging wall before or after slip, respectively. Note the lateral dynamic "gap" between the dotted and black line in case 2 . 

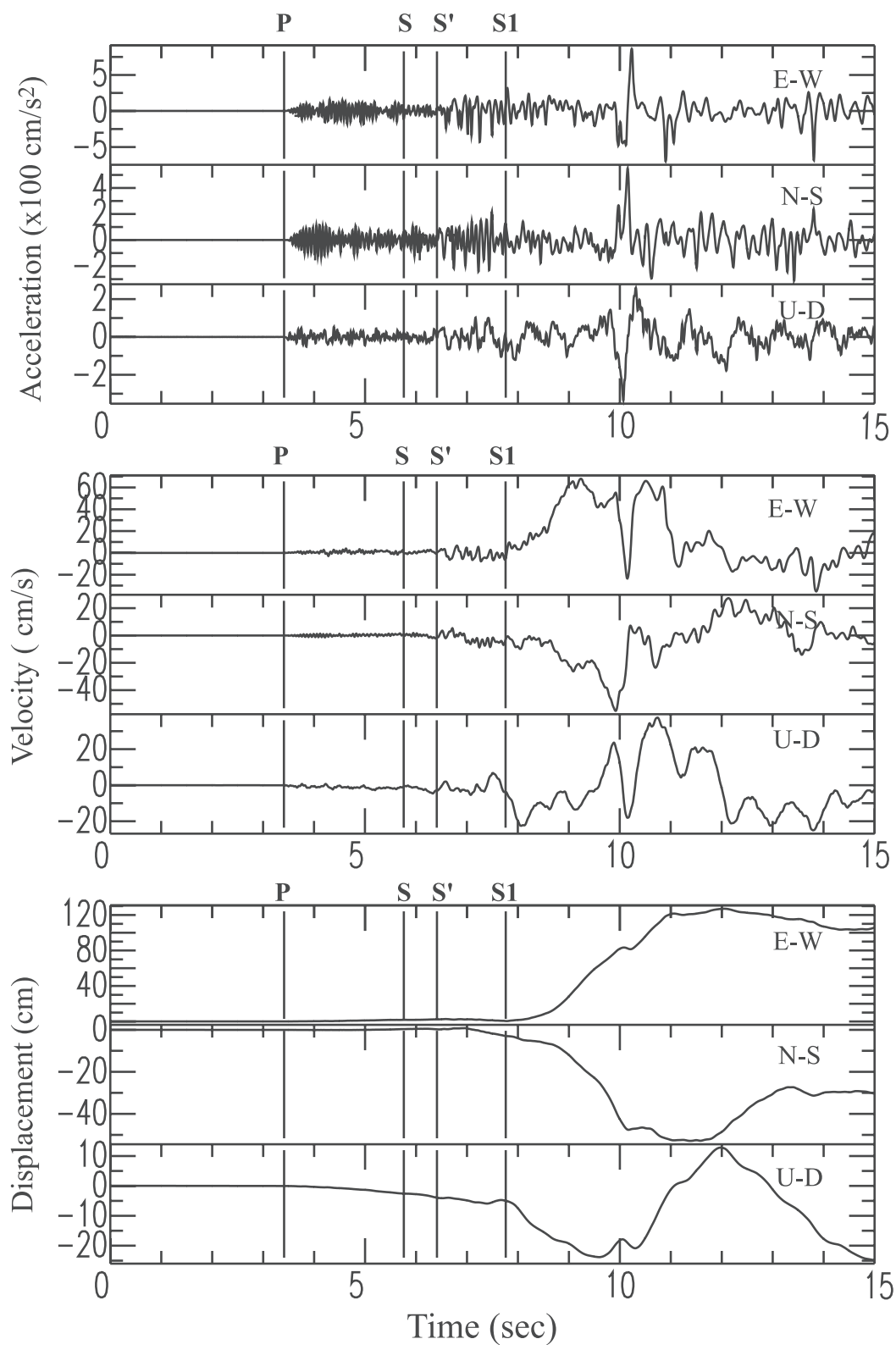

Figure A1. Three-component acceleration, velocity, and displacement records at station T129. The T129 station is located west of the epicenter, with a hypocentral distance of $16.2 \mathrm{~km}$ [Chen et al., 2001]. The four time marks $\mathrm{P}, \mathrm{S}, \mathrm{S}^{\prime}$, and $\mathrm{S} 1$ represent the hand-picked first arrival of the $P$ wave, the predicted $S$ arrival time, calculated with the $P$ arrival and the 1D velocity structure, the hand-picked $S$ arrival time, and the phase from the slip pulse nucleated near station T129, respectively.

it changes discretely with the half width of each time window, which is $1 \mathrm{~s}$ in these studies. This adds additional uncertainty to rupture velocity estimation. For instance, suppose that the real rupture of a particular subfault starts $0.5 \mathrm{~s}$ later than the beginning of its first time window; we would expect that, in the inverse result, the rupture time will still be the beginning of its first time window and thus a bias toward faster rupture velocities.

[46] The fault representation of Zeng and Chen [2001] is very similar to what we used here. The rupture initiation time becomes a free parameter, and the above bias is limited. However, the larger rupture velocity obtained by Zeng and Chen [2001] is probably caused by the difference in the data processing and alignment. In our study we aligned data by the $P$ wave first arrivals, while they used $S$ wave arrival instead. Because there is no report of a foreshock, it is probably safe to use $P$ waves instead of $S$ waves. As we discuss next, the $S$ wave from the hypocenter is notoriously difficult to pick.

[47] Taking advantage of many near-fault-trace records, Chen et al. [2001] attempted to estimate the rupture velocity directly by the differential time between the $S$ first arrival and the signal from a rupture pulse that nucleated from asperities near or underneath the stations. They found the rupture velocity varied from 2.28 to $2.69 \mathrm{~km} \mathrm{~s}^{-1}$, with an average of $\sim 2.49 \mathrm{~km} \mathrm{~s}^{-1}$. However, the result depends on the questionable pick of the hypocentral and energetic $S$ wave as well as on the $S$ wave velocity structure. For 
instance, the largest rupture velocity, $2.69 \mathrm{~km} \mathrm{~s}^{-1}$, is the average from the hypocenter to the T129 station. In Figure A1 we show the records at this station with four time marks. P shows the hand-picked first arrival of the $P$ wave. S shows the predicted $S$ arrival time, calculated with the $P$ arrival and the $1 \mathrm{D}$ velocity structure (Table 1 ). $\mathrm{S}^{\prime}$ and $\mathrm{S} 1$ mark the hand-picked $S$ arrival time and the phase from the slip pulse nucleated near station T129, as suggested by Chen et al. [2001], respectively. We find that the differential time between $\mathrm{S}^{\prime}$ and $\mathrm{S}$ is $0.65 \mathrm{~s}$, which is too large to be entirely attributed to errors in the velocity model, considering a small hypocentral distance of only $16.2 \mathrm{~km}$ [Chen et al., 2001]. If we agree with the time pick of the $S$ wave $\left(\mathrm{S}^{\prime}\right)$ and use a shear velocity of $3.46 \mathrm{~km} \mathrm{~s}^{-1}$, as did Chen et al. [2001], an extremely large $P$ wave velocity of $9.4 \mathrm{~km} \mathrm{~s}^{-1}$ would be required to satisfy the $S-P$ differential time, which is $2.9 \mathrm{~s}$ in the above conditions. Thus the pick of the $S$ wave $\left(S^{\prime}\right)$ is suspect, even though it looks reasonable. An alternate way to perform this work is to use a more reliable differential time between the $\mathrm{P}$ and $\mathrm{S} 1$ picks as well as the 1D layered velocity structure (Table 1). The rupture velocity along this path then becomes $2.1 \mathrm{~km} \mathrm{~s}^{-1}$, which is very close to what we obtain by the combined inversion. Because the difficulty in picking $S$ waves is a common feature, rupture velocities determined by Chen et al. [2001] are overestimated. On the basis of the new approach, the average rupture velocity drops to $\sim 2.0 \mathrm{~km} \mathrm{~s}^{-1}$.

[48] In a realistic Earth model the ratio of rupture velocity and shear velocity is not constant and varies with depth. The Chi-Chi rupture was concentrated in the top $10 \mathrm{~km}$. On the basis of the layered central Taiwan Earth model (Table 1), the average rupture velocity of $2.0 \mathrm{~km} \mathrm{~s}^{-1}$ is $\sim 66 \%$ of the shear velocity in a depth from 4 to $9 \mathrm{~km}$ and is $\sim 90-100 \%$ of the shear velocity in the top $4 \mathrm{~km}$. Therefore it is difficult to derive dynamic interpretations from this result only.

[49] Acknowledgments. We thank the Taiwan Central Weather Bureau for maintaining the strong motion network and S. B. Yu for the collection of GPS data. We are grateful for Hiroo Kanamori, Cliff Thurber, Steven Day, and an anonymous reviewer for helpful comments on this manuscript. This work is supported by NSF (EAR-0106701) and USGS (02HQGR0063). This is contribution 8450 of the Seismological Laboratory, Division of the Geological and Planetary Science, California Institute of Technology.

\section{References}

Aagaard, B. T., T. H. Heaton, and J. F. Hall, Dynamic earthquake ruptures in the presence of lithostatic normal stresses: Implications for friction models and heat production, Bull. Seismol. Soc. Am., 91, 1765-1796, 2001.

Angelier, J., Preface, Tectonophysics, 125, R9-R10, 1986.

Brune, J., Particle motions in a physical model of shallow angle thrust faulting, Proc. Indian Acad. Sci. Earth Planet. Sci., 105(2), L197L206, 1996.

Chen, K.-C., B.-S. Huang, J.-H. Wang, W.-G. Huang, T.-M. Chang, R.-D. Hwang, H.-C. Chiu, and C.-C. P. Tsai, An observation of rupture pulses of 20 September 1999 Chi-Chi, Taiwan, earthquake from near-field seismograms, Bull. Seismol. Soc. Am., 91, 1247-1254, 2001.

Chi, W., D. Dreger, and A. Kaverina, The finite source process of the Taiwan Chi-Chi earthquake using a dense strong motion dataset, Bull. Seismol. Soc. Am., 91, 1144-1157, 2001.

Du, Y. J., A. Aydin, and P. Segall, Comparison of various inversion techniques as applied to the determination of a geophysical deformation model for the 1983 Borah Peak earthquake, Bull. Seismol. Soc. Am., $82,1840-1866,1992$.

Dziewonski, A. M., G. Ekström, and N. N. Maternoskaya, Centroid moment tensor solutions for July-September 1999, Phys. Earth Planet. Inter., 119, 311-319, 2000.
Fossum, A. F., and L. B. Freund, Nonuniformly moving shear crack model for a shallow focus earthquake mechanism, J. Geophys. Res., 80, $3343-$ 3347, 1975.

Harris, R. A., and S. Day, Dynamic 3D simulations of earthquakes on en echelon faults, Geophys. Res. Lett., 26, 2089-2092, 1999.

Hartzell, S., P. Liu, and C. Mendoza, The 1994 Northridge, California, earthquake: Investigation of rupture velocity, risetime, and highfrequency radiation, J. Geophys. Res., 101, 20,091-20,108, 1996.

Heaton, T. H., Evidence for and implications of self-healing pulses of slip in earthquake ruptures, Phys. Earth Planet. Inter., 61, 1-20, 1990.

Hu, J.-C., J. Angelier, J.-C. Lee, T.-H. Chu, and D. Byrne, Kinematics of convergence, deformation and stress distribution in the Taiwan collision area: 2-D finite-element numerical modeling, Tectonophysics, 255, 243 268, 1996

Huang, B.-S., Two-dimensional reconstruction of the surface ground motions of an earthquake: The September 21, 1999, Chi-Chi, Taiwan earthquake, Geophys. Res. Lett., 27, 3025-3028, 2000.

Ji, C., D. V. Helmberger, T.-R. A. Song, K.-F. Ma, and D. J. Wald, Slip distribution and tectonic implication of the 1999 Chi-Chi, Taiwan, earthquake, Geophys. Res. Lett., 28, 4379-4382, 2001.

Ji, C., D. J. Wald, and D. V. Helmberger, Source description of the 1999 Hector Mine, California earthquake; part I: Wavelet domain inversion theory and resolution analysis, Bull. Seismol. Soc. Am., 92, $1192-$ $1207,2002 \mathrm{a}$.

Ji, C., D. J. Wald, and D. V. Helmberger, Source description of the 1999 Hector Mine, California earthquake; part II: Complexity of slip history, Bull. Seismol. Soc. Am., 92, 1208-1226, 2002 b.

Johnson, K. M., Y.-J. Hsu, P. Segall, and S.-B. Yu, Fault geometry and slip distribution of the 1999 Chi-Chi, Taiwan earthquake imaged from inversion of GPS data, Geophys. Res. Lett., 28, 2285-2288, 2001.

Kanamori, H., and T. H. Heaton, Microscopic and macroscopic physics of earthquakes, in GeoComplexity and the Physics of Earthquakes, Geophys. Monogr. Ser., vol. 120, edited by J. B. Rundle, D. L. Turcotte, and W. Klein, pp. 147-163, AGU, Washington, D. C., 2000.

Kao, H., and W.-P. Chen, The Chi-Chi Earthquake sequence: Active, out-of-sequence thrust faulting in Taiwan, Science, 288, 2346-2349, 2000 .

Kaverina, A., D. Dreger, and E. Price, The combined inversion of seismic and geodetic data for the source process of the 16 October $1999 M-w 7.1$ Hector Mine, California, earthquake, Bull. Seismol. Soc. Am., 92, 12661280, 2002.

Kostrov, B. V., Unsteady propagation of longitudinal shear cracks, J. Appl. Math. Mech.-USS, 30, 1241-1248, 1966.

Langston, C. A., and D. V. Helmberger, A procedure for modeling shallow dislocation sources, Geophys. J., 42, 117-130, 1975.

Lee, Y., Y. Sugiyama, T. Azuma, and Y. Kariya, Displacements and segmentation of the surface fault, 1999 Chi-Chi, Taiwan, earthquake, Eos Trans. $A G U, 81(48)$, Fall Meet. Suppl., Abstract S72B-08, 2000.

Liu, P., and R. J. Archuleta, A preliminary finite fault inversion of the 1999 M7.7 Chi-Chi, Taiwan earthquake using 3-D Green's functions, Eos Trans. $A G U$, 81(48), Fall Meet. Suppl., Abstract S71E-05, 2000.

Ma, K.-F., J.-H. Wang, and D.-P. Zhao, Three-dimensional seismic velocity structure of the crust and uppermost mantle beneath Taiwan, J. Phys. Earth, 44, 85-105, 1996.

Ma, K.-F., T.-R. A. Song, S.-J. Lee, and H.-I. Wu, Spatial slip distribution of the September 20,1999, Chi-Chi, Taiwan, earthquake $\left(M_{w} 7.6\right)$ : Inverted from teleseismic data, Geophys. Res. Lett., 27, 3417-3420, 2000 .

Ma, K.-F., J. Mori, S. Lee, and S.-B. Yu, Rupture process of the 1999 Chi-Chi, Taiwan, earthquake from strong motion, teleseismic and GPS data, Bull. Seismol. Soc. Am., 91, 1069-1087, 2001.

Magistrale, H., and S. Day, Three-dimensional simulations of multisegment thrust fault rupture, Geophys. Res. Lett., 26, 2093-2096, 1999.

Ni, S., J. N. Brune, G. Choy, J. G. Anderson, and Y. Zeng, Local and teleseismic estimates of radiated energy and apparent stress from the Ch-Chi, Taiwan earthquake: Evidence for inertial detachment of the hanging wall from the footwall in thrust faulting (poster), Eos Trans. $A G U, 80(46)$, Fall Meet. Prog., 13, 1999.

Oglesby, D. D., R. Archuleta, and S. Nielsen, Earthquakes on dipping faults: The effects of broken symmetry, Science, 280, 1055-1059, 1998.

Oglesby, D. D., R. J. Archuleta, and S. B. Nielsen, Dynamics of dip-slip faulting: Explorations in two dimensions, J. Geophys. Res., 105, 13,643$13,653,2000$.

Scholz, C. H., (Ed.), The Mechanics of Earthquakes and Faulting, 439 pp., Cambridge Univ. Press, New York, 1990.

Segall, P., and D. D. Pollard, Mechanics of discontinuous faults, J. Geophys. Res., 88, 555-568, 1983.

Sen, M. K., and P. L. Stoffa, Nonlinear one-dimensional seismic waveform inversion using simulated annealing, Geophysics, 56, 1624-1638, 1991. 
Seno, T., S. Stein, and A. E. Gripp, A model for the motion of the Philippine Sea plate consistent with NUVEL-1 and geological data, J. Geophys. Res., 98, 17,941-17,948, 1993.

Sibson, R. H., Stopping of earthquake ruptures at dilational fault jogs, Nature, 316, 248-251, 1985

Sipkin, S. A., C. G. Bufe, and M. D. Zirbes, Moment-tensor solution estimated using optimal filter theory: Global seismicity 1999, Phys. Earth Planet. Inter, 122, 147-159, 2000.

Wald, D. J., and T. H. Heaton, Spatial and temporal distribution of slip for the 1992 Landers, California, earthquake, Bull. Seismol. Soc. Am., 84, $668-691,1994$

Wu, C.-J., M. Takeo, and S. Ide, Source process of the Chi-Chi earthquake: A joint inversion of strong motion data and global positioning system data with a multi-fault model, Bull. Seismol. Soc. Am., 91, 1128-1143, 2001.

Yu, S. B., H. Y. Chen, and L. C. Kuo, Velocity field of GPS stations in the Taiwan area, Tectonophysics, 274, 41-59, 1997.
Yu, S.-B., et al., Pre-seismic deformation and co-seismic displacements associated with the 1999 Chi-Chi, Taiwan earthquake, Bull. Seismol. Soc. Am., 91, 995-1012, 2001.

Zeng, Y., and C. Chen, Fault rupture process of the September 20, 1999 Chi-Chi, Taiwan earthquake, Bull. Seismol. Soc. Am., 91, 1088-1099, 2001 .

D. V. Helmberger and C. Ji, Seismological Laboratory 252-21, Division of Geological and Planetary Sciences, California Institute of Technology, Pasadena, CA 91125, USA. (helm@gps.caltech.edu; jichen@gps.caltech. edu)

K.-F. Ma, Institute of Geophysics, National Central University, 100 Chung-Da Road, Chung-Li 320-54, Taiwan. (kuofongm@yahoo.com.tw)

D. J. Wald, U.S. Geological Survey, Denver Federal Center, P.O. Box 25046, MS966, Lakewood, CO 80225, USA. (wald@usgs.gov) 

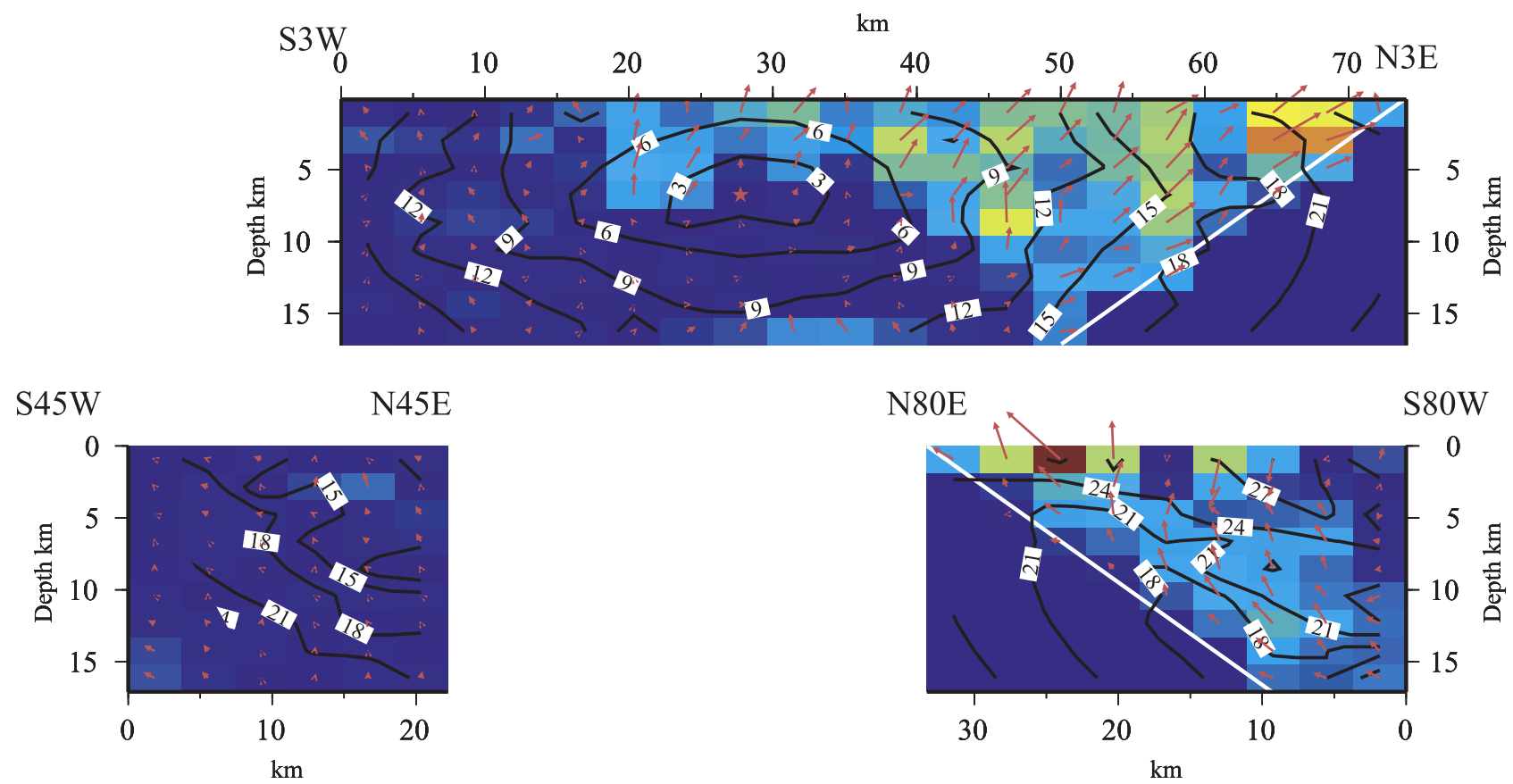

Slip distribution (Azimuth E20S, Elevation 18)
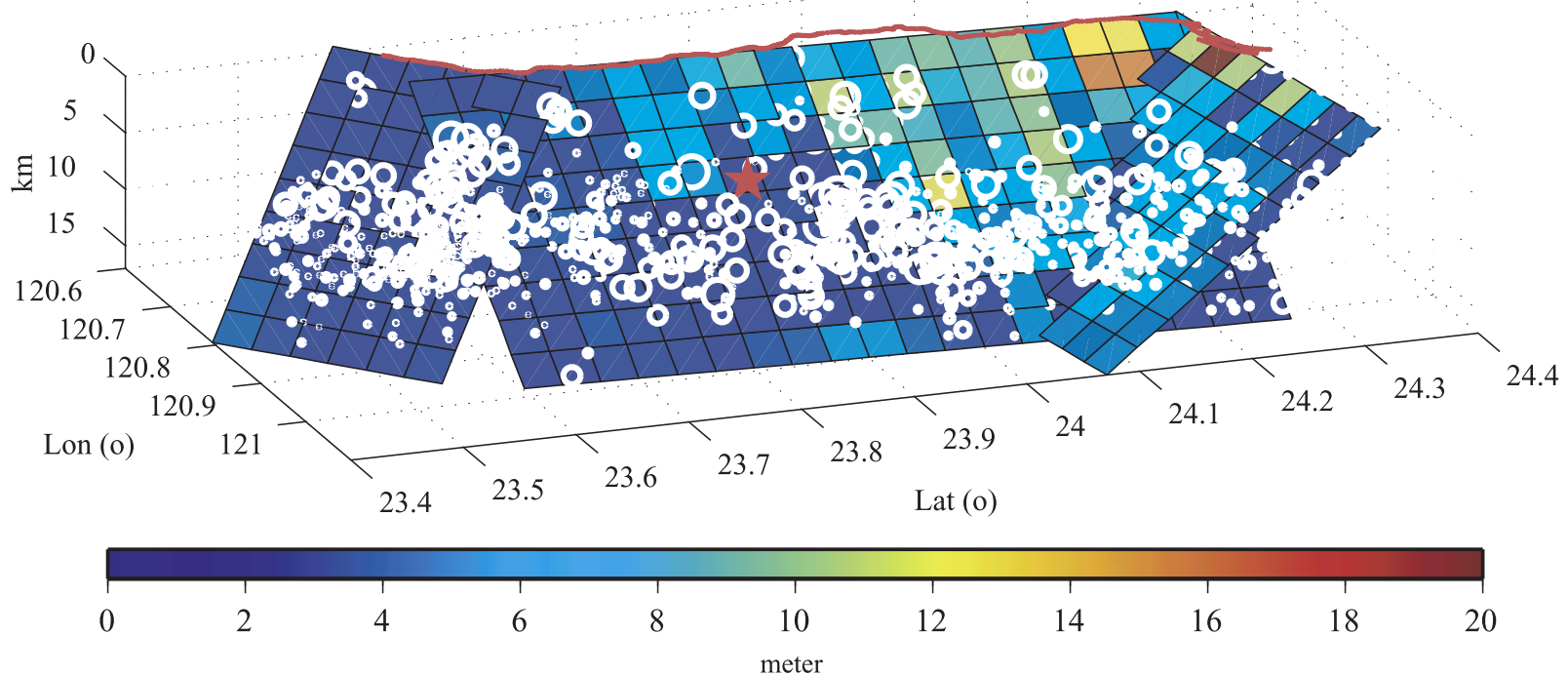

Figure 4. 2D and 3D views of the preferred combined inverse model. (top) The slip distribution in a planar view. Fault 1 is on the top, and fault 2 and fault 3 are on the lower-right and lower-left portions, respectively (Figure 2). Fault 1 and fault 2 cross each other, and the black line on the fault planes indicates the intersection. The color bar shows the amount of slip, the arrows indicate the slip vectors, and the contours display the rupture initiation time. (bottom) 3D view of the same slip distribution. 

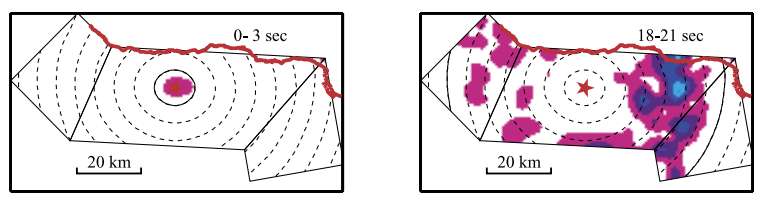

(m)
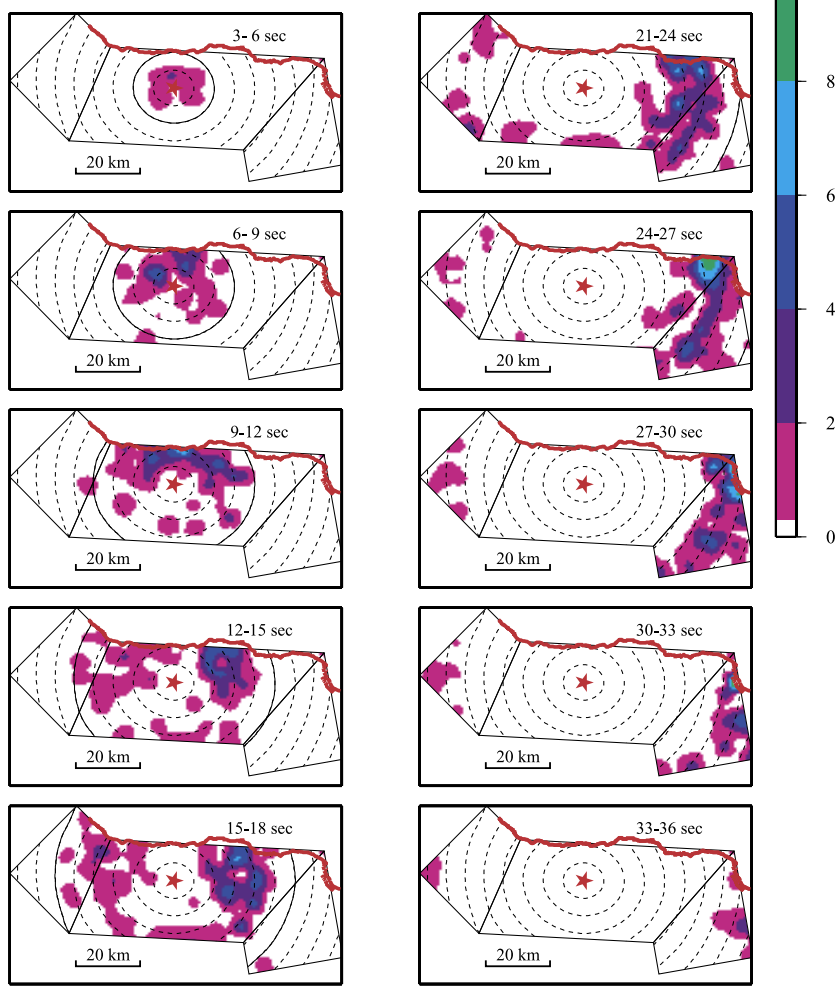

Figure 9. Snapshots of the 1999 Chi-Chi earthquake source rupture at every $3 \mathrm{~s}$. The numbers at the upper right corner of each panel indicate the time interval of this snapshot. A color bar shows the amount of slip during this period. A red star indicates the location of the hypocenter, and the red lines show the surface trace. Note that the dashed contours show the positions of the rupture fronts with a speed of $2.1 \mathrm{~km} \mathrm{~s}^{-1}$ every $3 \mathrm{~s}$, and a solid contour specifies the rupture front with the same speed at the end of each snapshot.

Figure 10. (opposite) Map views of the rupture characteristics of the preferred model. Only the subfaults with $>1 \mathrm{~m}$ slip ( $5 \%$ of the peak slip) are displayed because the risetime of subfaults with weaker slip is hard to constrain reliably. Red lines show the surface break and black lines show adjacent major faults named ChungHua, Chelungpu, ShuangTung, and LiShan from west to east, respectively. The pink triangles show near-fault strong motion stations. (a) Risetime distribution on the base map of local topography. The color bar shows the risetime values. (b) Distribution of the $t_{s} / t_{e}$ ratios. (c) Slip distribution. The color bar shows the slip offsets. The aftershocks are plotted in circles whose sizes are proportional to the $M_{L}$ of the events. There are three low-slip zones on fault 1, indicated by red arrows. Note the aftershock cluster east of the hypocenter (region A) and the small cluster south of station T071 (see the text). (d) Slip velocity distribution. The color bar shows the peak slip velocity. 
JI ET AL.: SLIP HISTORY OF THE 1999 CHI-CHI EARTHQUAKE
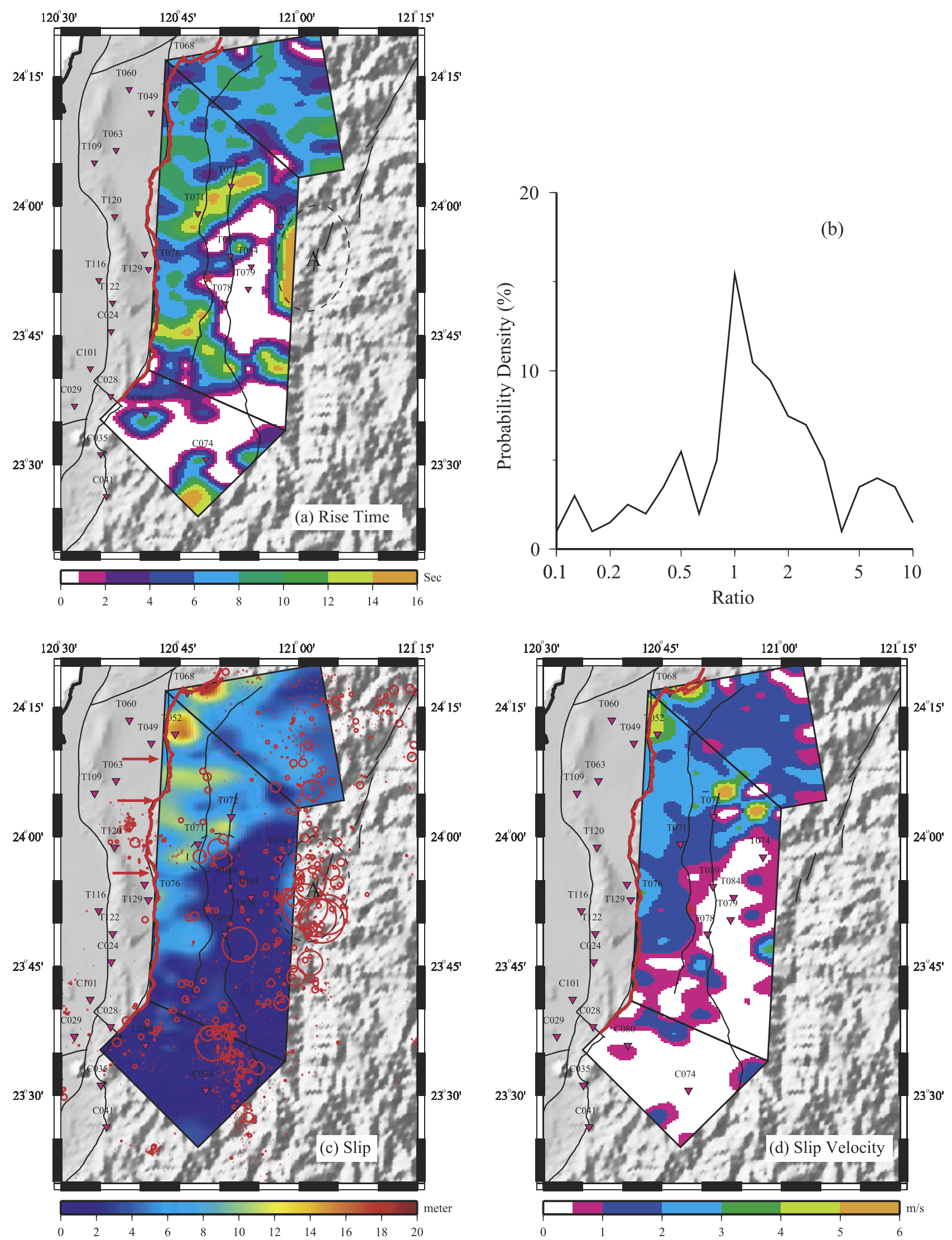

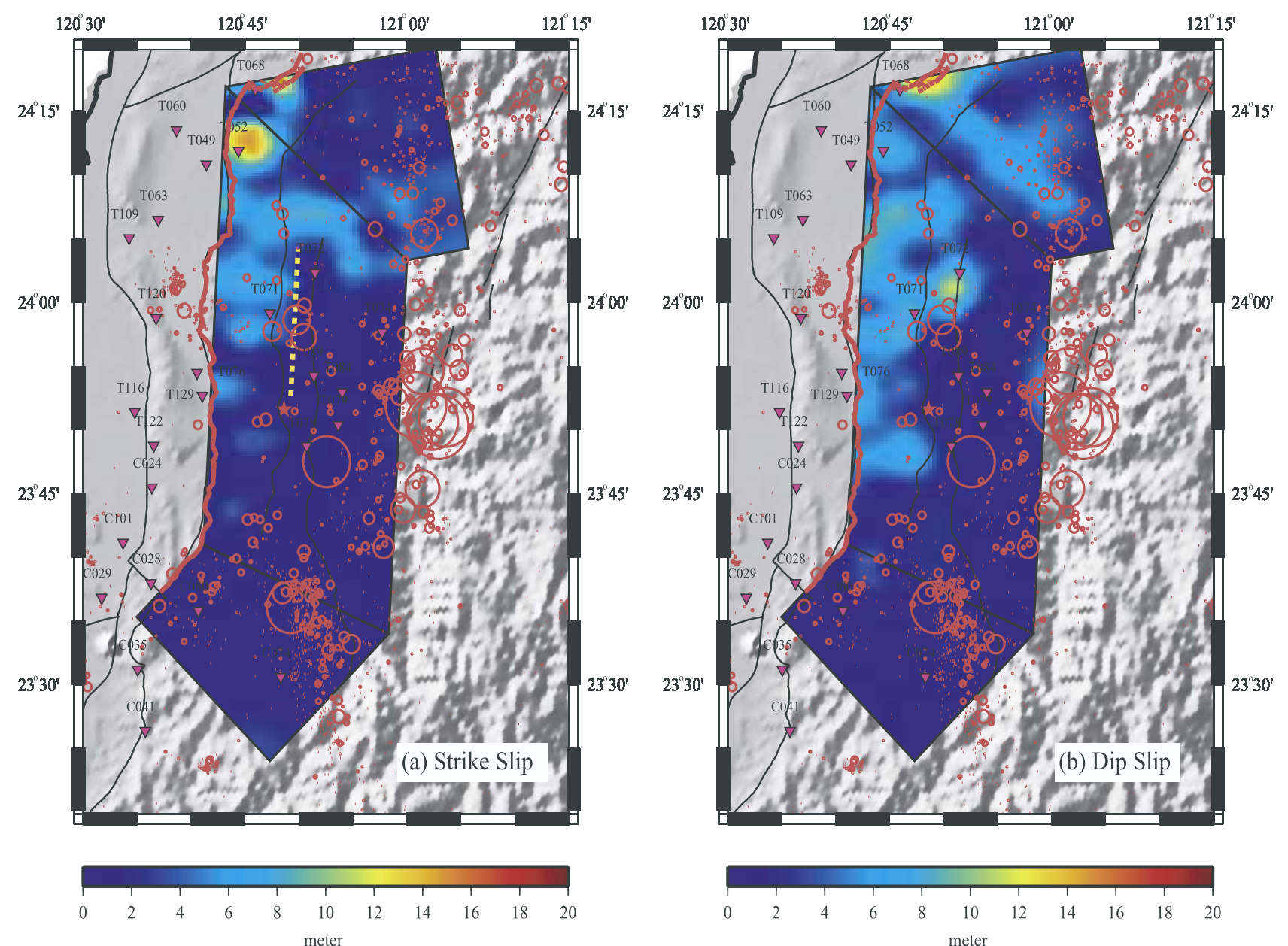

Figure 11. Slip decomposition. The oblique motion of the Chi-Chi earthquake is separated into (a) strike-slip and (b) dip-slip components. The color bar shows slip amplitudes, and circles indicate the aftershocks. A yellow dashed line shows the surface projection of an isodepth line of $8 \mathrm{~km}$ on the Chelungpu fault. Note that the amplitudes of strike-slip motions are comparable with those of the dip-slip motions, and the strike-slip motions on fault 1 around the "bulge" of the surface break are shallower than $8 \mathrm{~km}$. 